Michele Feitoza-Silva $^{1}$
Patrícia Fernandes da Silva Nobre $^{1}$
André Luis Gemal $^{2}$
Katia Christina Leandro ${ }^{1}$

\title{
REGULAMENTAÇÃO DOS MATERIAIS MÉDICOS NO BRASIL
}

Medical supplies regulations in Brazil

\footnotetext{
${ }^{1}$ Instituto Nacional de Controle de Qualidade em Saúde. Rio de Janeiro/RJ, Brasil.

${ }^{2}$ Universidade Federal do Rio de Janeiro. Rio de Janeiro/RJ, Brasil.

Correspondência: Michele Feitoza-Silva. E-mail: mifeitoza@yahoo.com.br.
}

Recebido em: 21/01/2016. Revisado: 12/04/2016. Revisado novamente: 19/09/2016. Aprovado: 22/09/2016. 


\section{RESUMO}

Os produtos sob regime de vigilância sanitária classificados como "produtos para saúde" compreendem os "materiais médicos". Atos regulatórios de 1999 a 2005 foram selecionados e classificados por assunto, possibilitando discutir o perfil dessas publicações. A classificação foi conduzida avaliando cada legislação, sua ementa e texto publicado em Diário Oficial da União. Para subsidiar a discussão, propomos uma classificação em oito assuntos (temas). A partir dela, foi possível correlacionar e demonstrar a prevalência de assuntos publicados e, assim, indicar uma tendência de temas contemplados em cada ano do período avaliado. Como reflexão, entendemos que o Sistema Nacional de Vigilância Sanitária, neste caso, possui uma oportunidade de atuação única devido a seu arcabouço normativo organizado, capaz de atender a campos de atuação como registro, boas práticas, tramitações relacionadas às empresas de âmbito sanitário e pós-comercialização. No entanto, as legislações apresentadas somente terão aplicabilidade e eficiência se existir o conhecimento atualizado por parte dos profissionais de saúde das normas gerais de vigilância sanitária que apoiem processos decisórios de gestão mais eficientes, sem prejuízo da segurança da população.

\section{Palavras-Chave}

Agência Nacional de Vigilância Sanitária; Legislação; Materiais Médicos; Regulação.

\section{ABSTRACT}

Products under health surveillance classified as "products for health" comprehend the "medical supplies". Regulatory acts issued from 1999 to 2005 were selected and classified by subject enabling the discussion of these publications' profiles. The classification was made by evaluating each legislation, its agenda and the text published in the Diário Oficial da União, the government's official gazette in Brazil. To help the discussion we proposed a classification in eight subjects (themes). In this way, it was possible to correlate and demonstrate the prevalence of published subjects indicating a tendency of the themes contemplated in every year of the period under evaluation. As a reflection, we believe that in this case, there is a unique oportunity for the Brazilian Health Regulatory Agency taking action due to its organized normative framework, with applicability to fields like registration, good practices, issues related to companies in the health business and post-marketing. However, these legislation will only be applicable and efficient if there is up-to-date knowledge among the health care professionals about general health surveillance standards that support more efficient management decision-making processes, without jeopardizing the safety of the population.

\section{Keywords}

Brazilian Health Regulatory Agency; Legislation; Medical Supplies; Regulations. 


\section{Introdução}

A consolidação do Sistema Único de Saúde (SUS) no Brasil tem como um de seus requisitos fundamentais a organização de um subsistema de vigilância sanitária (Visa) que tenha capacidade de normatizar, monitorar e fiscalizar produtos e serviços consumidos de interesse de saúde, nas prestações tanto privadas quanto públicas, incluindo o consumidor final (cadeia de produção e consumo). Assim, seriam concretizadas as recomendações da Organização Mundial da Saúde (OMS) pertinentes à promoção e à prevenção de saúde como um direito de todos ${ }^{1}$. No caso brasileiro, o acesso aos serviços de saúde é um direito social, formalizado em contraprestações do Estado ao cidadão individualmente considerado ou a grupos específicos ${ }^{2,3}$.

Eventos negativos de grande repercussão na mídia nos anos 1990 colocaram em evidência a fragilidade da organização da Visa então em vigor e criaram condições políticas para uma mudança institucional: a transição da Visa da administração direta para a indireta, sob forma de autarquia especial, a Agência Nacional de Vigilância Sanitária (Anvisa), criada em 19994. Essa mudança supostamente expressou o interesse brasileiro por uma abordagem menos cartorial do setor produtivo da saúde, considerando a dinâmica econômica do mercado (fusões, incorporações e aquisições de empresas, as quais, não obstante o interesse de saúde, têm natureza competitiva e são de competência do Conselho Administrativo de Defesa Econômica [Cade]) e a dinâmica tecnológica (novos produtos, meios de produção e controle etc.), para os quais se passou a discutir mecanismos legais e regulatórios em virtude de sua especificidade e que naturalmente demandam uma burocracia técnica de alto nível ${ }^{5,6}$.

O contexto emergente dessa reforma institucional teve o objetivo de adicionar segurança e transparência ao mercado, contribuir para o desenvolvimento

\footnotetext{
${ }^{1}$ ALMEIDA FILHO, Naomar Monteiro de. O conceito de saúde e a vigilância sanitária: notas para a compreensão de um conjunto organizado de práticas de saúde. In: SEMINÁRIO TEMÁTICO PERMANENTE DA AGÊNCIA NACIONAL DE VIGILÂNCIA SANITÁRIA, 1., Brasília-DF, out. 2000. Brasília-DF: Ministério da Saúde, 2000. Disponivel em: <https://repositorio.ufba.br/ri/bitstream/ri/13870/1/Almeida\%20Filho\%20N.\%200\%20 CONCEITO\%2ODE\%20SA\%c3\%9aDE.pdf>.

${ }^{2}$ CARVALHO, Mariana Siqueira de. A saúde como direito social fundamental na Constituição Federal de 1988. Revista de Direito Sanitário, São Paulo, v. 4, n. 2, p. 15-31, 2013. Disponível em: <http://www.revistas.usp. br/rdisan/article/view/81181>. http://dx.doi.org/10.11606/issn.2316-9044.v4i2p15-31.

${ }^{3}$ LEAL, Rogério Gesta A quem compete o dever de saúde no direito brasileiro? Esgotamento de um modelo Institucional. Revista de direito Sanitário, São Paulo, v. 9, n. 1, p. 50-69, 2008. Disponível em: <http://www. revistas.usp.br/rdisan/article/view/13101>. http://dx.doi.org/10.11606/issn.2316-9044.v9i1p50-69.

4PIOVESAN Márcia Franke. A construção política da Agência Nacional de Vigilância Sanitária. 2005. Dissertação. (Mestrado em Saúde Pública) - Escola Nacional de Saúde Pública - ENSP -FIOCRUZ, Rio de Janeiro, 2005.

${ }^{5}$ MORAES, Reginaldo. Estado, mercado e outras instituições reguladoras. Lua Nova, São Paulo, n. 58, p. 121 140, 2003. Disponível em: <http://www.scielo.br/pdf/In/n58/a07n58.pdf>. http://dx.doi.org/10.1590/ S0102-64452003000100007.

${ }^{6}$ PIOVESAN Márcia Franke, LABRA, Maria Eliana. Institutional change and political decision-making in the creation of the Brazilian National Health Surveillance Agency. Cad. Saúde Pública, v. 23, n. 6, p. 1373-1382, 2007. Disponível em: <http://www.scielo.br/pdf/csp/v23n6/11.pdf>. http://dx.doi.org/10.1590/S0102-311X2007000600012.
} 
econômico e social do país e melhorar a qualidade de produtos e serviços, buscando reduzir e controlar os riscos sanitários potenciais aos quais a população é exposta em decorrência da cadeia de produção ${ }^{7}$.

\section{Produtos para a saúde}

Os produtos sob regime de Visa classificados como "Produtos para saúde" (PS) compreendem os produtos médicos (PM) e aqueles denominados produtos diagnósticos de uso in vitro ${ }^{8}$.

Produto médico (PM): equipamento, aparelho, material, artigo ou sistema de uso ou aplicação médica odontológica ou laboratorial, destinado a prevenção, diagnóstico, tratamento, reabilitação ou anticoncepção e que não utiliza meio farmacológico, imunológico ou metabólico para realizar sua principal função em seres humanos, podendo, entretanto, ser auxiliado em suas funções por tais meios?.

Os PMs são divididos em quatro classes de risco, de acordo com a finalidade de uso e considerando-se o risco que representam à saúde do consumidor, do paciente, do operador ou de terceiros envolvidos na utilização Para o enquadramento dos PMs em uma das quatro classes, devem ser aplicadas 18 regras de classificação descritas no Anexo II da Resolução da Diretoria Colegiada (RDC) 185/2001. As classes são: I - baixo risco; II - médio risco; III - alto risco; e IV - máximo risco.

\section{Ações por nível de gestão}

A regulamentação dos PSs e das ações da Visa é responsabilidade das três esferas de governo, observadas as competências dos níveis de gestão e a descentralização de atividades, como definido pelo SUS ${ }^{10}$. A esfera federal é representada pela Anvisa, que coordena o Sistema Nacional de Vigilância Sanitária (SNVS), controla as atividades de autorização de funcionamento de empresa (AFE) vinculada ao Cadastro Nacional de Pessoa Jurídica (CNPJ) e todos os trâmites regulatórios necessários para o registro ou cadastro dos $\mathrm{PSs}^{11}$. As demais esferas - estado e

\footnotetext{
${ }^{7}$ AGÊNCIA NACIONAL DE VIGILÂNCIA SANITÁRIA - ANVISA. Regulação Sanitária. Disponível em: <http://portal. anvisa.gov.br/wps/portal/anvisa/anvisa/regulacaosanitaria>. Acesso em: 05 set. 2015.

${ }^{8}$ AGÊNCIA NACIONAL DE VIGILÂNCIA SANITÁRIA. Resolução RDC n, 185, de 22 de outubro de 2001. Regulamento Técnico que consta no anexo desta Resolução, que trata do registro, alteração, revalidação e cancelamento do registro de produtos médicos na Agência Nacional de Vigilância Sanitária. Diário Oficial da União, 24 out. 2001.

9ld. Ibid.

${ }^{10}$ BRASIL. Lei n. 8.080, de 19 de setembro de 1990. Dispõe sobre as condições para a promoção, proteção e recuperação da saúde, a organização e o funcionamento dos serviços correspondentes e dá outras providências. Diário Oficial da União, 20 set. 1990.

${ }^{11}$ CENTRO DE VIGILÂNCIA SANITÁRIA. A vigilância sanitária de produtos para saúde. Disponível em: <http:// www.cvs.saude.sp.gov.br/apresentacao.asp?te_codigo=3>. Acesso em: 05 set. 2015.
} 
município - lidam, principalmente, com a fiscalização, embora articuladas entre si para todos os outros aspectos.

Para melhor compreensão do sentido de regulação e regulamentação (objeto principal deste estudo), vale destacar que regulamentar significa a edição de normas de natureza infralegal com o objetivo de explicar e dar cumprimento à lei, sendo de maneira geral regulamentos executivos expedidos por uma agência reguladora ${ }^{12,13,14}$. Por outro lado, regulação, usando a definição de Levi-Faur ${ }^{15}$, é ex ante a legalização burocrática de regras prescritivas e o monitoramento e aplicação dessas regras por atores sociais, empresariais e políticos. Tais regras serão consideradas regulamentação desde que não sejam formuladas diretamente por um legislador (direito primário) ou por tribunais (veredicto, julgamento, decisão e adjudicação). Em outras palavras, a regulamentação é sobre burocracia e administração de regras administrativas, e não sobre a definição de regras legislativas ou judiciais ${ }^{16}$. Assim, as ações da Anvisa, enquanto são de natureza formal regulamentar, têm como efeito operar a regulação de um determinado setor ${ }^{17,18}$.

A Anvisa tem desenvolvido diversas ações para aprimorar a qualidade da regulamentação elaborada, como, por exemplo, a Agenda Regulatória e a Análise de Impacto Regulatório (AIR $)^{19}$. Essas práticas regulatórias, à luz de uma nova agenda de reformas que já vem sendo incentivada e promovida pelo governo brasileiro em termos de governança e melhoria da regulação, estimulam o aprofundamento no estudo das regulamentações e seus desdobramentos ${ }^{20}$. A Agenda Regulatória, por exemplo, é um mecanismo que está sendo amplamente difundido com o objetivo de

${ }^{12}$ GAETANI, Francisco, ALBUQUERQUE, Kélvia. Análise de impacto regulatório e melhoria regulatória. In: RAMALHO P. I. S. (Org.). Regulação e agências reguladoras: governança e análise de impacto regulatório Brasília-DF: Anvisa, 2009. p. 189-196. Disponível em: <http://portal.anvisa.gov.br/wps/wcm/connect/98 29b700474586958fccdf3fbc4c6735/8Regulacao.pdf?MOD=AJPERES>. Acesso em: 05 set. 2015.

${ }^{13}$ DI PIETRO, Maria Sylvia Zanella. Direito administrativo. 13. ed. São Paulo: Atlas, 2001.

${ }^{14}$ FERRAZ JUNIOR, Tercio Sampaio. Poder normativo das agências reguladoras à luz do princípio da eficiência. In: ARAGÃO, A. S. de (Coord.). O poder normativo das Agências Reguladoras. Rio de Janeiro: Forense, 2006. p. 271-297.

${ }^{15}$ LEVI-FAUR, Davi. Regulation and regulatory governance. In: LEVI FAUR, Davi (Ed.) Hand book on the politics of Regulation. Cheltenham, UK: Edward Elgar Publishing, 2011. p. 3-20.

${ }^{16}$ MORAES, Eliana Aparecida Silva. 0 poder regulamentar e as competências normativas conferidas à Agência Nacional de Vigilância Sanitária. Revista de Direito Sanitário, São Paulo, v. 2, n. 1, p. 39-56, 2001. Disponível em: <https://www.revistas.usp.br/rdisan/article/view/13086>. http://dx.doi.org/10.11606/ issn.2316-9044.v2i1p39-56.

${ }^{17}$ MOREIRA, Egon Bockmann. Os limites à competência normativa das agências reguladoras. In: ARAGÃO, A. S. de (Coord.). O poder normativo das Agências Reguladoras. Rio de Janeiro: Forense, 2006. p. 173-220.

${ }^{18}$ BRASIL. Lei n. 6.360, de 23 de setembro de 1976. Dispõe sobre a Vigilância Sanitária a que ficam sujeitos os Medicamentos, as Drogas, os Insumos Farmacêuticos e Correlatos, Cosméticos, Saneantes e Outros Produtos, e dá outras Providências. Diário Oficial da União, 24 set. 1976.

${ }^{19}$ CENTRO DE VIGILÂNCIA SANITÁRIA. A vigilância sanitária de produtos para saúde, cit.

${ }^{20}$ SILVA, Gustavo Henrique Trindade da. Agenda regulatória e análise de impacto regulatório: a experiência da Agência Nacional de Vigilância Sanitária na aplicação prática de instrumentos inovadores de previsibilidade, transparência e accountability. In: CONGRESSO CONSAD DE GESTÃO PÚBLICA, 4, 2011, Brasília. Anais... Brasília-DF, 2011. 
sistematizar e ampliar a transparência e a participação da sociedade. Já a AIR, com métodos e técnicas específicos para as decisões da agência, pode ser compreendida no contexto da regulação como um processo de gestão de riscos regulatórios com foco em resultados. Esses instrumentos, aliados a reuniões públicas, processos de incorporação de mecanismos de participação social e elaboração de cartas de serviços ao cidadão, se alinham à Política Regulatória Nacional e, ao mesmo tempo, a conformam ${ }^{21,22}$.

A partir disso, objetivou-se apresentar um painel cronológico das legislações que impactam a regulação normativa dos materiais médicos, propondo parâmetros de classificação para os atos publicados por tipo de tema e discutindo a prevalência por ano de publicação.

\section{Metodologia}

Neste trabalho, apresentamos um perfil dos atos regulamentares posteriores ao surgimento da Anvisa especificamente para os materiais médicos, conforme adotado pela própria agência em sua estrutura organizacional - excluindo, portanto, os equipamentos eletromédicos e os conjuntos de diagnóstico in vitro.

O painel será apresentado por meio de uma tabela cronológica, que, além de elencar os atos regulatórios, possibilitou classificá-los por assunto e, por conseguinte, discutir o perfil dessas publicações de 1999 a 2015.

A classificação foi conduzida avaliando cada legislação, sua ementa e o texto publicado em Diário Oficial da União (DOU). As oito possibilidades de classificação estão, neste estudo, vinculadas ao assunto do ato. Para subsidiar a discussão, propomos a classificação conforme o Quadro 1.

A partir dessa classificação, foi possível correlacionar e demonstrar a frequência de assuntos publicados e, portanto, indicar uma tendência de temas. Logo, a cada ano avaliado é possível observar a importância/destaque que a Visa deu a cada tema.

Considerando, todavia, que atos regulamentares demandam embasamento legal, isto é, leis ou outras normas que lhes sejam superiores e que lhes justifiquem a existência, faz-se mister oferecer uma visão geral do ordenamento jurídico da Visa e sua institucionalização.

\footnotetext{
${ }^{21}$ SILVA, Gustavo Henrique Trindade da. op. cit.

${ }^{22}$ ALVES, Flávia Neves Rocha; PECl, Alketa. Análise de Impacto Regulatório: uma nova ferramenta para a melhoria da regulação na Anvisa. Revista de Saúde Pública, São Paulo, v. 45, n. 4, p. 802-805, ago. 2011. Disponível em: <http://www.revistas.usp.br/rsp/article/view/33019>. Acesso em: 21 mar. 2017. doi:http://dx.doi.org/10.1590/S0034-89102011000400023.
} 
Quadro 1 - Temas e assuntos

\begin{tabular}{|c|l|}
\hline Temas & Assunto \\
\hline 1 & Avaliações, taxas e regras econômicas. \\
2 & Boas Práticas de Fabricação (BPF) e controle e assuntos relacionados. \\
3 & Normas para registro, definições e regras para grupos/famílias e determinações quanto \\
4 & à classificação para registro/cadastro. \\
5 & Segurança e eficácia. \\
6 & Regulamentos técnicos específicos. \\
7 & tramitações sobre a Câmara Técnica. \\
8 & Regras sobre importação que impactam materiais médicos. \\
\hline
\end{tabular}

Para a construção do painel regulatório, utilizamos como base o arcabouço legal disponível no site da Anvisa, que foi complementado - já que, por vezes, o item era citado como ação de complementação/alteração (revogava ou substituía), mas não aparecia como item a ser contabilizado e avaliado.

\section{Resultados}

\section{Leis e decretos de Visa que orientam a regulação de materiais médicos}

Em 1976, a Lei n. 6.360 foi publicada e caracterizada como um regulamento de vanguarda por alguns autores. Tratou do tema Visa, oferecendo definições, objeto, campo de atuação, poderes e competências para que autoridades com poder de polícia interferissem tanto no setor privado quanto na atuação de outros entes públicos ${ }^{23}$.

É uma legislação de texto claro e, apesar de datar dos anos 1970, as várias alterações que sofreu não modificaram o conjunto de conceitos centrais - registro dos produtos, AFE, Visa pós-uso, Responsável Técnico (RT), entre outros -, demonstrando sua importância para a prática de Visa ${ }^{24}$.

Em 1977, houve a publicação da Lei n. 6.437, que trata de infrações sanitárias e processo administrativo fiscal sanitário e que ainda hoje, é para os profissionais do âmbito sanitário uma espécie de aliado de trabalho. Serve como parâmetro para as instâncias estaduais e municipais e é bem abrangente, referindo-se a infrações que

\footnotetext{
${ }^{23}$ BRASIL. Lei n. 6.360, de 23 de setembro de 1976, cit.

${ }^{24}$ Id. Ibid.
} 
possam ocorrer em todo setor regulado sob regime de Visa. Seu texto foi alterado pela Lei n. 9.695/1998 e pela Medida Provisória (MP) n. 2.190-34/200125,26,27.

A proposta de garantia de qualidade, ou qualidade total, assim como a eficácia (ou eficiência) e a segurança também foram reafirmadas como um direito de todo cidadão pela Constituição de 1988 e pelo Código de Defesa do Consumidor, Lei n. 8.078/1990 ${ }^{28,29}$. A Lei n. 8.080/1990, chamada Lei Orgânica da Saúde, cria o SUS e oferece definições importantes - no caso da Visa, a sua própria definição e alcance de objetos ${ }^{30}$.

Em 1999, a Lei n. 9.782 cria o SNVS e a Anvisa, a qual tem a competência de exercer a coordenação do SNVS. A Portaria do MS n. 1.378/2013 estabelece a composição e as competências de cada ente do SNVS: no âmbito federal, a Anvisa, com a participação indireta das autoridades de saúde estaduais e municipais do Conselho Nacional de Secretários Estaduais de Saúde (Conass), do Conselho Nacional de Secretários Municipais de Saúde (Conasems) e dos laboratórios centrais de saúde pública ${ }^{31,32,33}$.

Em 2013, o Decreto n. 8.077 revogou o Decreto n. 79.094/1977, regulamentador da Lei n. 6.360/1976 e, apesar de tratar fundamentalmente dos mesmos assuntos, tem uma apresentação mais direta e coloca para a Anvisa a responsabilidade de trabalhar as questões mais técnicas, evitando o processo longo da administração direta e do legislativo ${ }^{34,35,36}$.

${ }^{25}$ BRASIL. Lei n. 6.437, de 20 de agosto de 1977. Configura as infrações à legislação sanitária federal, estabelece as sanções respectivas, e dá outras providências. Diário Oficial da União, 24 ago.1977.

${ }^{26}$ BRASIL. Lei n. 9.695, de 20 de agosto de 1998. Acrescenta incisos ao art. $1^{\circ}$ da Lei $n^{\circ} 8.072$, de 25 de julho de 1990 , que dispõe sobre os crimes hediondos, e altera os arts. $2^{\circ}, 5^{\circ}$ e $10^{\circ}$ da Lei $n^{\circ} 6.437$, de 20 de agosto de 1977, e dá outras providências. Diário Oficial da União, 21 ago.1998.

${ }^{27}$ BRASIL. Medida Provisória n. 2190-34, de 23 de agosto de 2001. Altera dispositivos das Leis n 9.782, de 26 de janeiro de 1999, que define o Sistema Nacional de Vigilância Sanitária e cria a Agência Nacional de Vigilância Sanitária, e 6.437, de 20 de agosto de 1977, que configura infrações à legislação sanitária federal e estabelece sanções respectivas, e dá outras providências. Diário Oficial da União, 25 ago. 1998.

${ }^{28}$ BRASIL. Constituição da República Federativa do Brasil de 1988. Disponível em: <http://www.planalto.gov. br/ccivil_03/constituicao/constituicao.htm>. Acesso em: 31 out. 2017.

${ }^{29}$ BRASIL. Lei n. 8.078, de 19 de setembro de 1990. Dispõe sobre a proteção do consumidor e dá providências. Diário Oficial da União, 12 set. 1990.

${ }^{30}$ BRASIL. Lei n. 8.080, de 19 de setembro de 1990, cit.

${ }^{31}$ BRASIL. Lei n. 9.782, de 26 de janeiro de 1999. Define o Sistema Nacional de Vigilância Sanitária, cria a Agência Nacional de Vigilância Sanitária, e dá outras providências. Diário Oficial da União, 27 jan. 1999.

${ }^{32}$ BRASIL. Portaria n. 1.378, de 09 de julho de 2013. Regulamenta as responsabilidades e define diretrizes para execução e financiamento das ações de Vigilância em Saúde pela União, Estados, Distrito Federal e Municípios, relativos ao Sistema Nacional de Vigilância em Saúde e Sistema Nacional de Vigilância Sanitária. Diário Oficial da União, 10 jul. 2013.

${ }^{33}$ LUCCHESE, Geraldo A vigilância sanitária no Sistema Único de Saúde. In: DE SETA, Marismary Horsth; PEPE, Vera Lúcia Edais; OLIVEIRA, Gisele O'Dwyer de (Orgs.). Gestão e vigilância sanitária: modos atuais do pensar e fazer. Rio de Janeiro: Fiocruz, 2006. p.33-47.

${ }^{34}$ BRASIL. Lei n. 6.360 , de 23 de setembro de 1976, cit.

${ }^{35}$ BRASIL. Decreto n. 8.077, de 14 de agosto de 2013. Regulamenta as condições para o funcionamento de empresas sujeitas ao licenciamento sanitário, e o registro, controle e monitoramento, no âmbito da vigilância sanitária, dos produtos de que trata a Lei no 6.360, de 23 de setembro de 1976, e dá outras providências. Diário Oficial da União, 15 ago. 2013.

${ }^{36}$ BRASIL. Decreto n. 79.094, de 5 de janeiro de 1977. Regulamenta a Lei $n^{\circ} 6360 / 76$, que submete a sistema de vigilância sanitária os medicamentos, insumos farmacêuticos, drogas, correlatos, cosméticos, produtos de higiene, saneantes e outros. Diário Oficial da União, 5 jan. 1977. 


\section{Outros atos em Visa de materiais médicos}

A criação da Anvisa e sua visibilidade na sociedade ofereceram uma oportunidade de evolução das normas sanitárias e isso repercutiu não apenas na área de medicamentos, mas também na de PS, objeto deste estudo.

Como exemplo, temos as RDCs da Anvisa, que são atos que possuem eficácia jurídica para normatizar os objetos e processos sujeito à Visa sob competência da Anvisa ${ }^{37}$.

A Tabela 1 está organizada cronologicamente a partir de 1999 por tipo, número e ano do ato regulatório. $\mathrm{O}$ assunto/ementa também está descrito/a na tabela, além da análise do ato normativo - que, também realizada para embasar este estudo, serve para nortear a classificação proposta de assuntos. A natureza dos atos foi classificada como "Nova" ou "Revisão (Rev.)"; no caso de revisão e as modificações foram apresentadas. Ainda na tabela, o status do ato também é apresentado como: "Vigente $(\mathrm{V})$ ", "Vigente com alterações $\left(\mathrm{V}^{\star}\right)$ " ou "Revogada (R)"; no caso de revogada, também é possível observar a(s) alteração(ões) publicada(s) posteriormente.

Foram selecionadas para este artigo as normas referentes a "Materiais" ou PMs, uma das subáreas da área de PS que originalmente também inclui kits para diagnóstico in vitro, equipamentos médicos e materiais odontológicos. Assuntos vinculados ao reprocessamento de materiais médicos não foram incluídos. Os atos apresentados são RDCs, Resoluções Específicas (RE) ou Instruções Normativas (IN).

\section{Discussão}

\section{Apresentação e discussão da tabela cronológica}

Em dezembro de 1999 foi publicada a RDC 27, que prorrogou a isenção de taxas de concessão de certificação de BPF, registro ou renovação para microempresas; é o único ato de 1999 na Tabela 1 impactando o assunto "materiais médicos", essencialmente por questões de custo para empresas ${ }^{38}$.

\footnotetext{
${ }^{37}$ RAMALHO, Pedro Ivo Sebba. Insulamento burocrático, accountability e transparência: dez anos de regulação da Agência Nacional de Vigilância Sanitária. Revista de Serviço Público, Brasília, v. 60, n. 4, p. 337-364, out./dez. 2009.

${ }^{38}$ AGÊNCIA NACIONAL DE VIGILÂNCIA SANITÁRIA - ANVISA. Estoque regulatório da Anvisa. Macrotema produtos para a saúde. Disponível em: <http://portal.anvisa.gov.br/wps/wcm/connect/ d1a159004776681a8874aa97f5c37773/Estoque+Regulat\%C3\%B3rio+PRODUTOS+P+SAUDE. xlsx?MOD=AJPERES>. Acesso em: $16 \mathrm{dez} .2015$.
} 





Feitoza-Silva M., Nobre P. F. S., Gemal A. L., Leandro K. C.

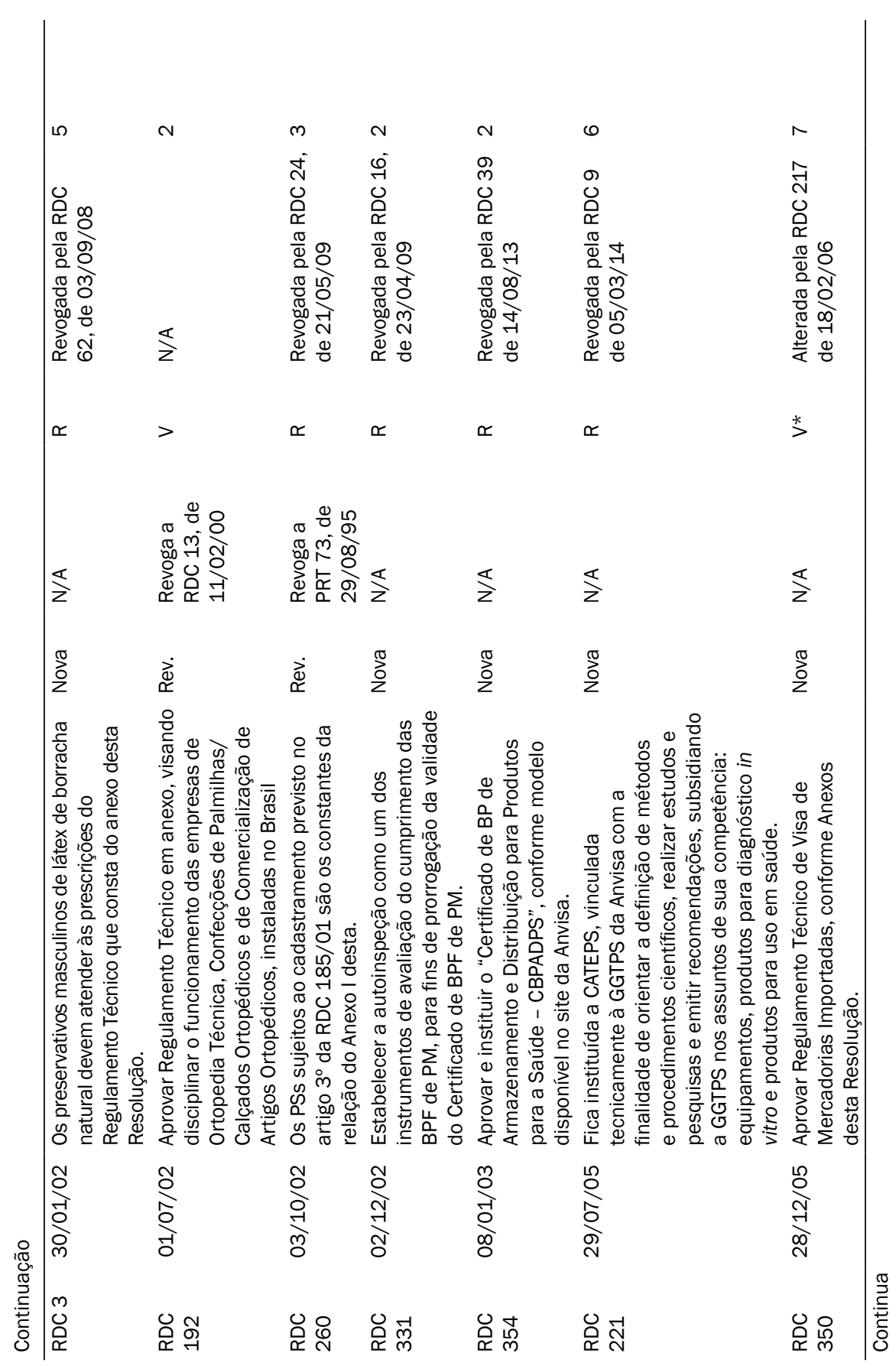




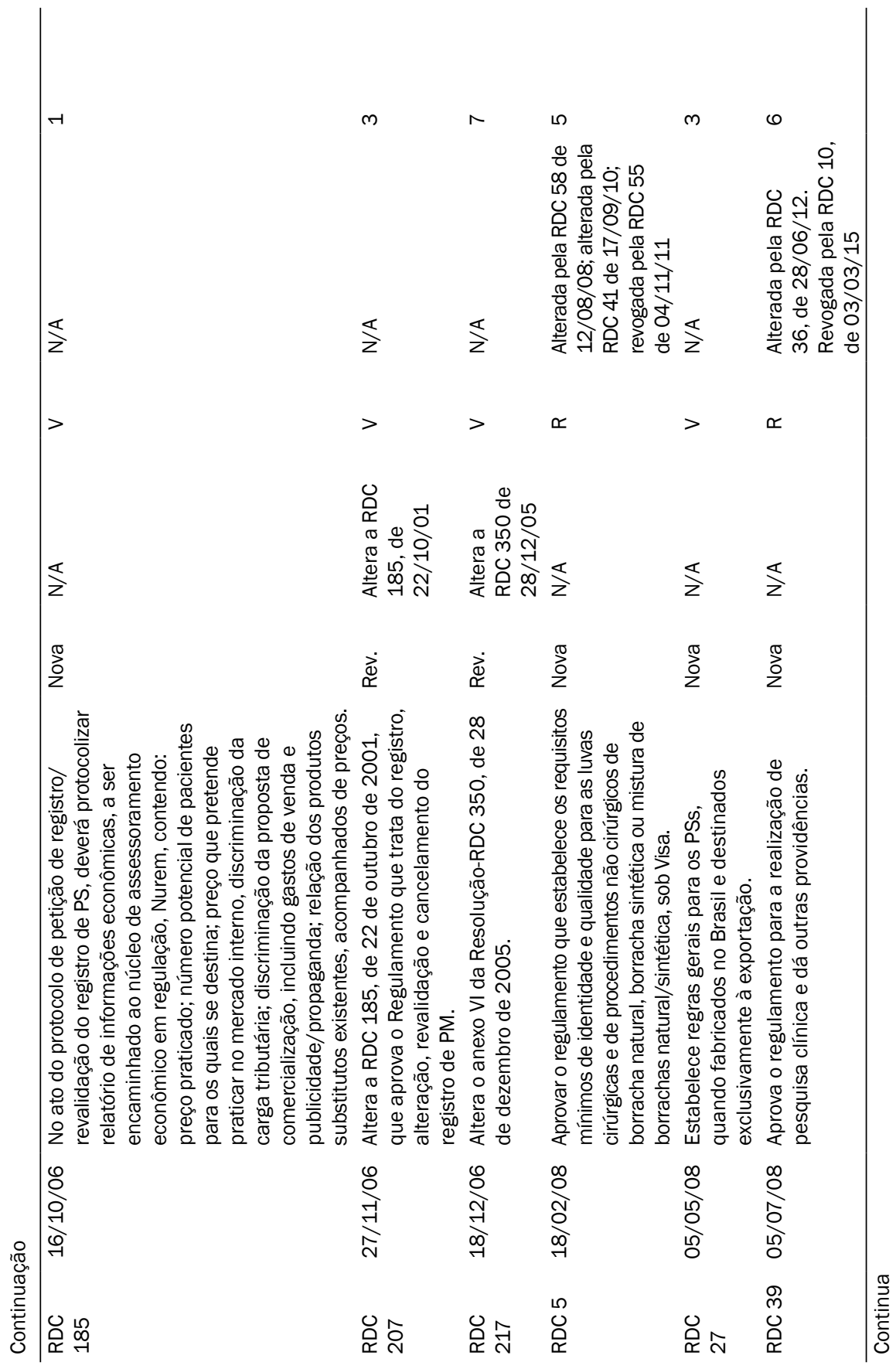


Feitoza-Silva M., Nobre P. F. S., Gemal A. L., Leandro K. C.

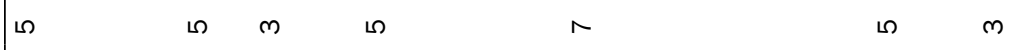



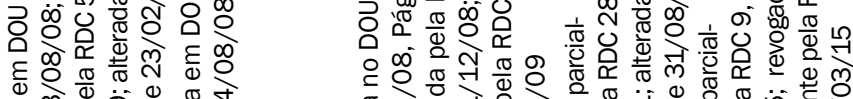

त

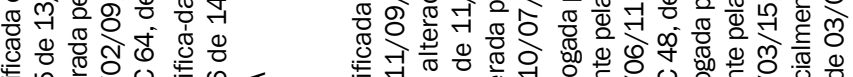

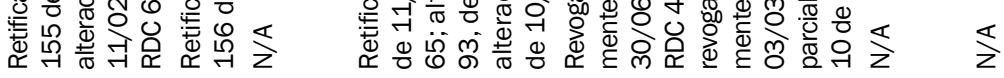
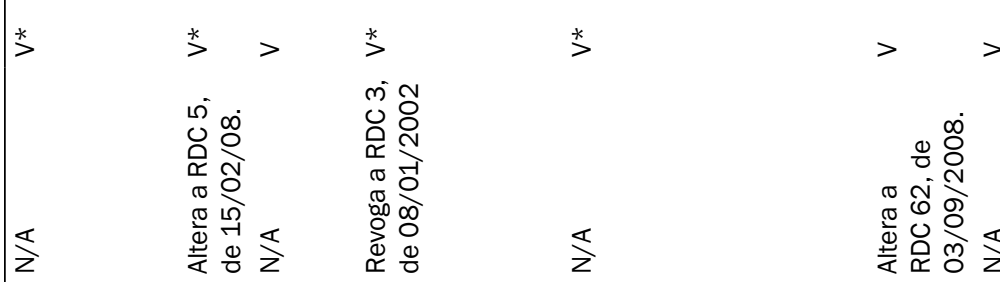

กั ำ

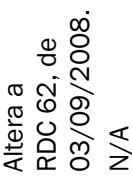

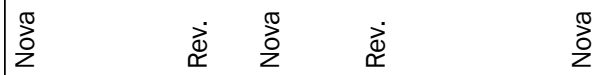

खi $\quad$ o

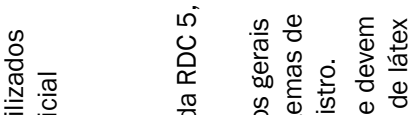

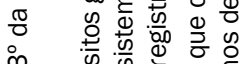

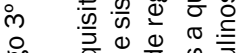



क

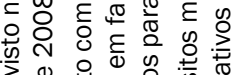

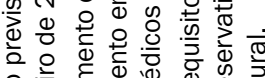

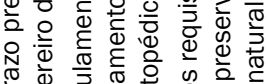

तั



$\Sigma$

$\frac{10}{2}$

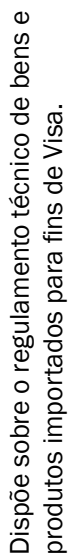

$\frac{10}{0}$

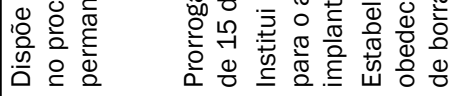

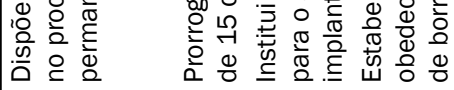

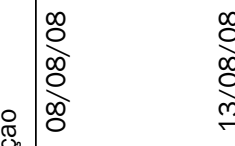

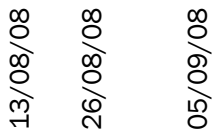

$\stackrel{\infty}{\stackrel{2}{2}}$

员

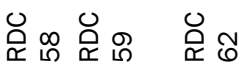

오 어

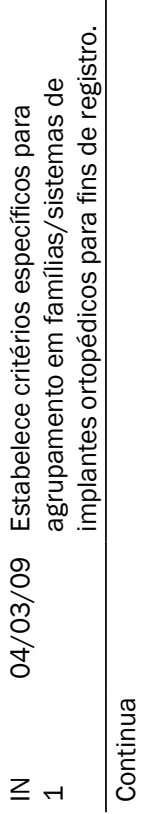


Regulamentação dos materiais médicos no Brasil

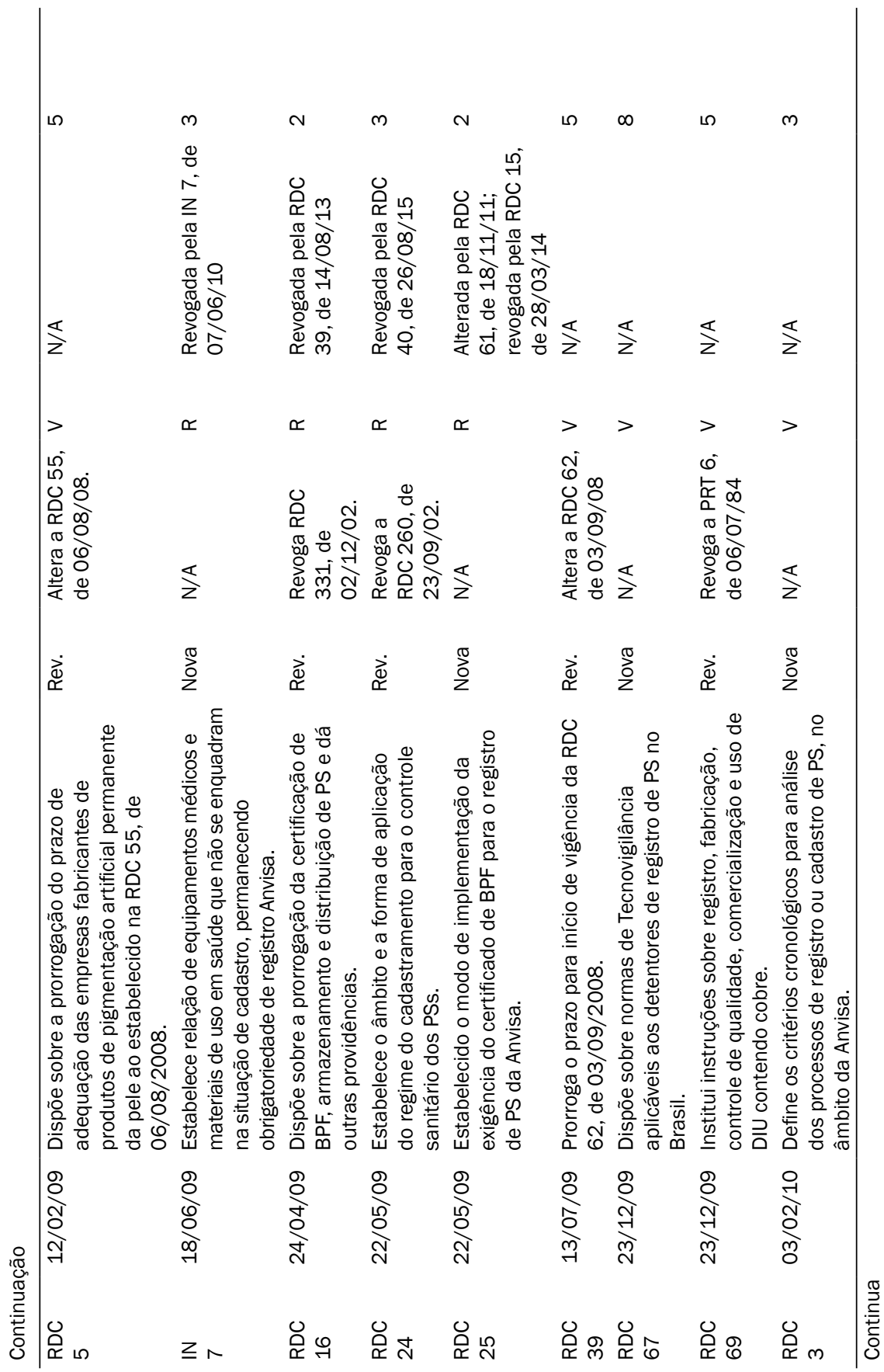


Feitoza-Silva M., Nobre P. F. S., Gemal A. L., Leandro K. C.

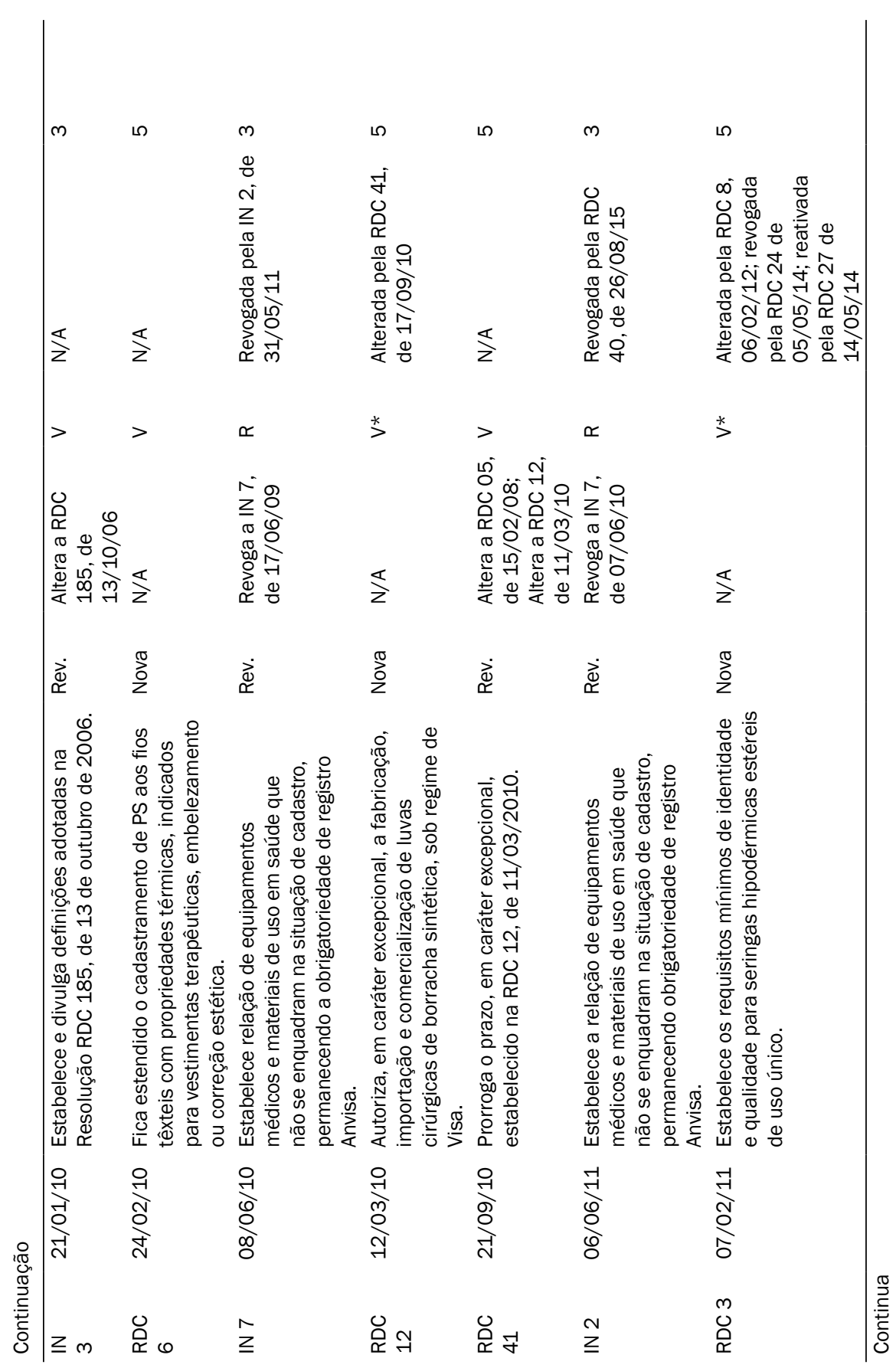


Regulamentação dos materiais médicos no Brasil

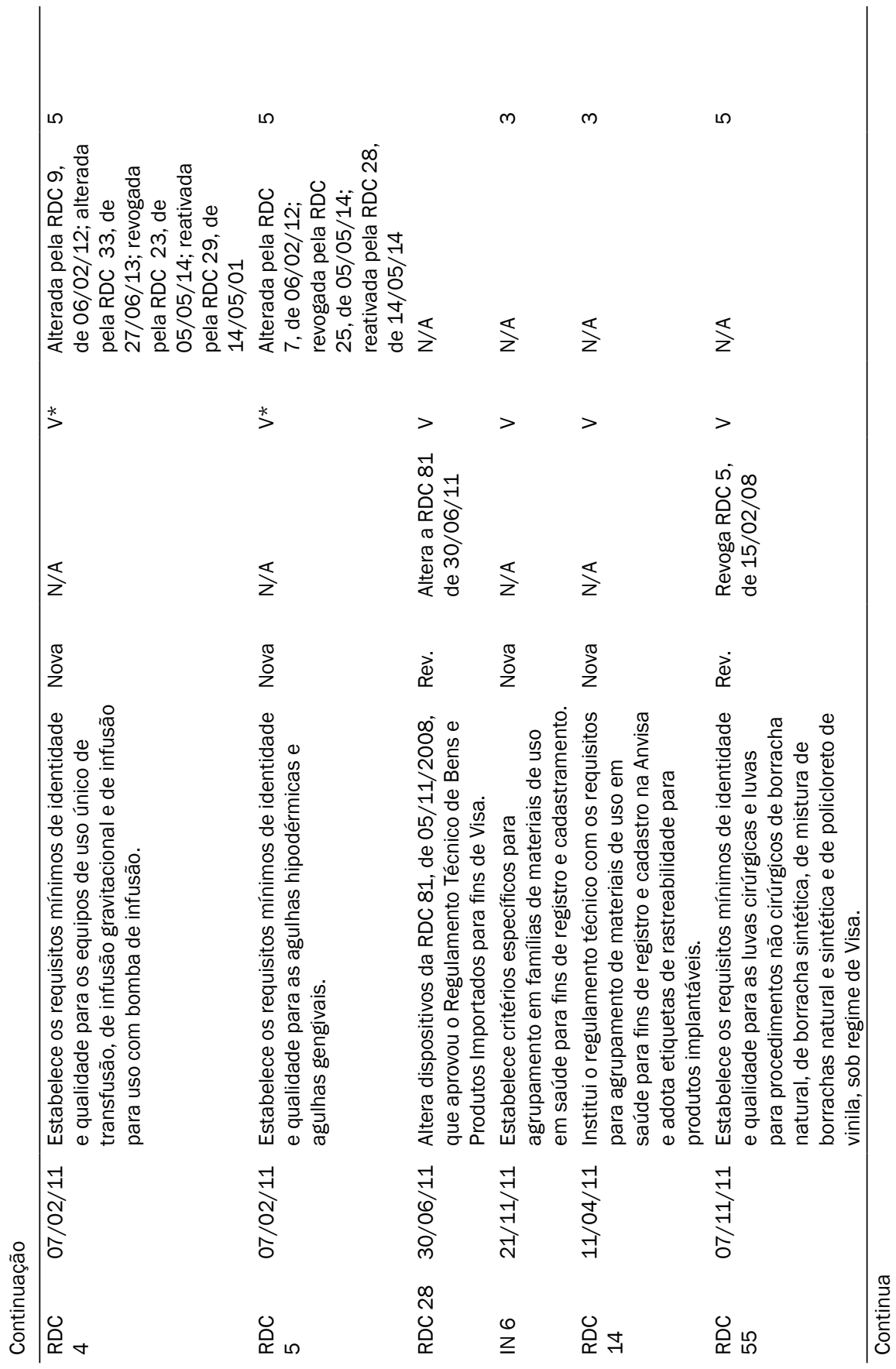


Feitoza-Silva M., Nobre P. F. S., Gemal A. L., Leandro K. C.

\begin{tabular}{|c|c|c|c|c|c|c|}
\hline 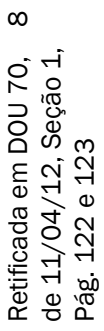 & $\begin{array}{l}m \\
\vdots \\
z\end{array}$ & $\stackrel{\mathbb{z}}{z}$ & 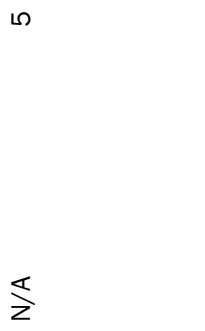 & 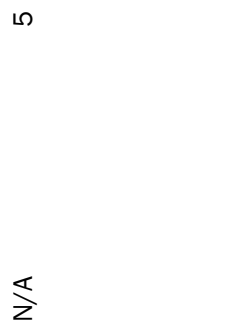 & 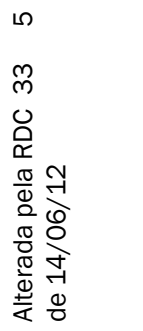 & 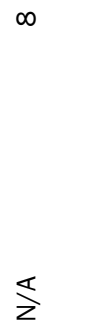 \\
\hline$\stackrel{*}{>}$ & $>$ & $>$ & $>$ & $>$ & $\stackrel{*}{>}$ & $>$ \\
\hline$\frac{\pi}{z}$ & 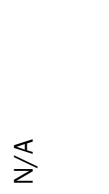 & 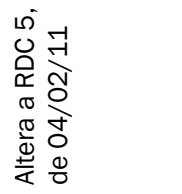 & 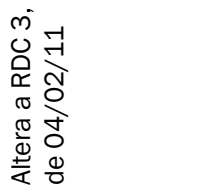 & 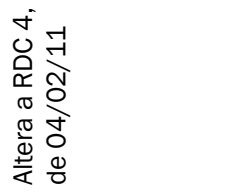 & $\stackrel{\Sigma}{z}$ & 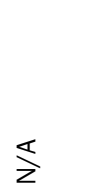 \\
\hline$\frac{\pi}{2}$ & $\frac{\pi}{2}$ & $\dot{\ddot{\varpi}}$ & $\dot{\vec{\varpi}}$ & $\dot{\vec{\varpi}}$ & $\frac{\pi}{2}$ & $\frac{\pi}{0}$ \\
\hline  &  & 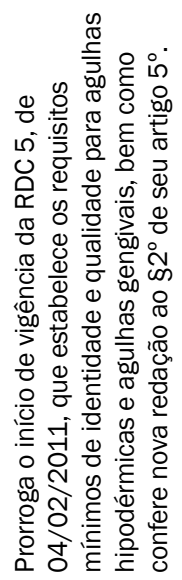 & 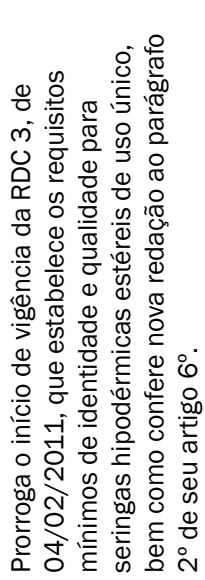 & 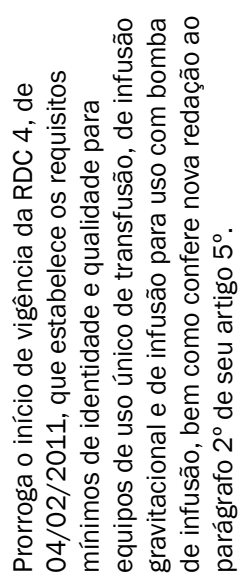 & 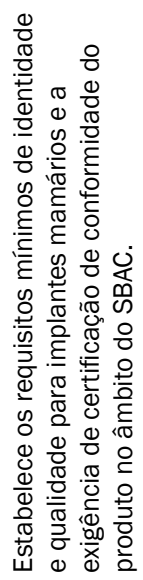 & 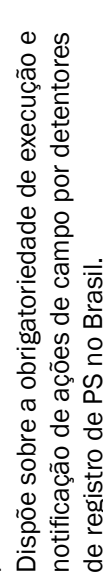 \\
\hline  & $\begin{array}{l}\text { సै } \\
\stackrel{\leftrightarrow}{\circ} \\
\stackrel{\circ}{न े}\end{array}$ & $\begin{array}{l}\text { ָै } \\
\text { तิ } \\
\text { ลิ }\end{array}$ & 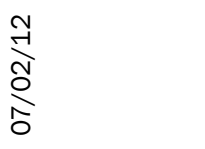 & 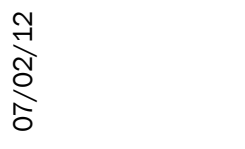 &  & $\begin{array}{l}\text { フै } \\
\text { ঠे } \\
\text { ๖े }\end{array}$ \\
\hline-1 & $\geqq \sigma$ & 足 & $\begin{array}{l}\text { O } \\
\text { Q } \infty\end{array}$ & 足 & 足 & $\stackrel{\text { On }}{\sim}$ \\
\hline
\end{tabular}


Regulamentação dos materiais médicos no Brasil

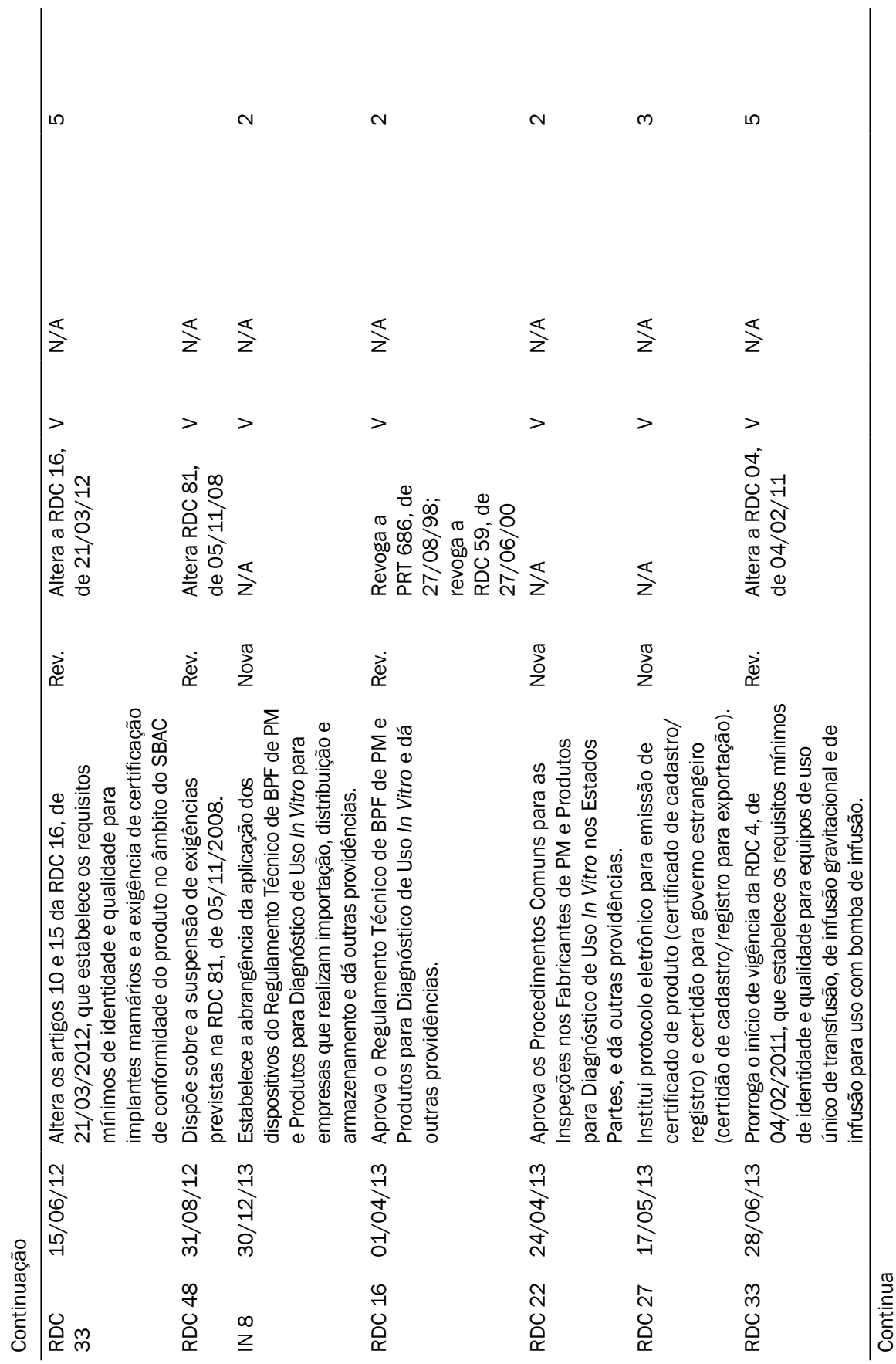


Feitoza-Silva M., Nobre P. F. S., Gemal A. L., Leandro K. C.

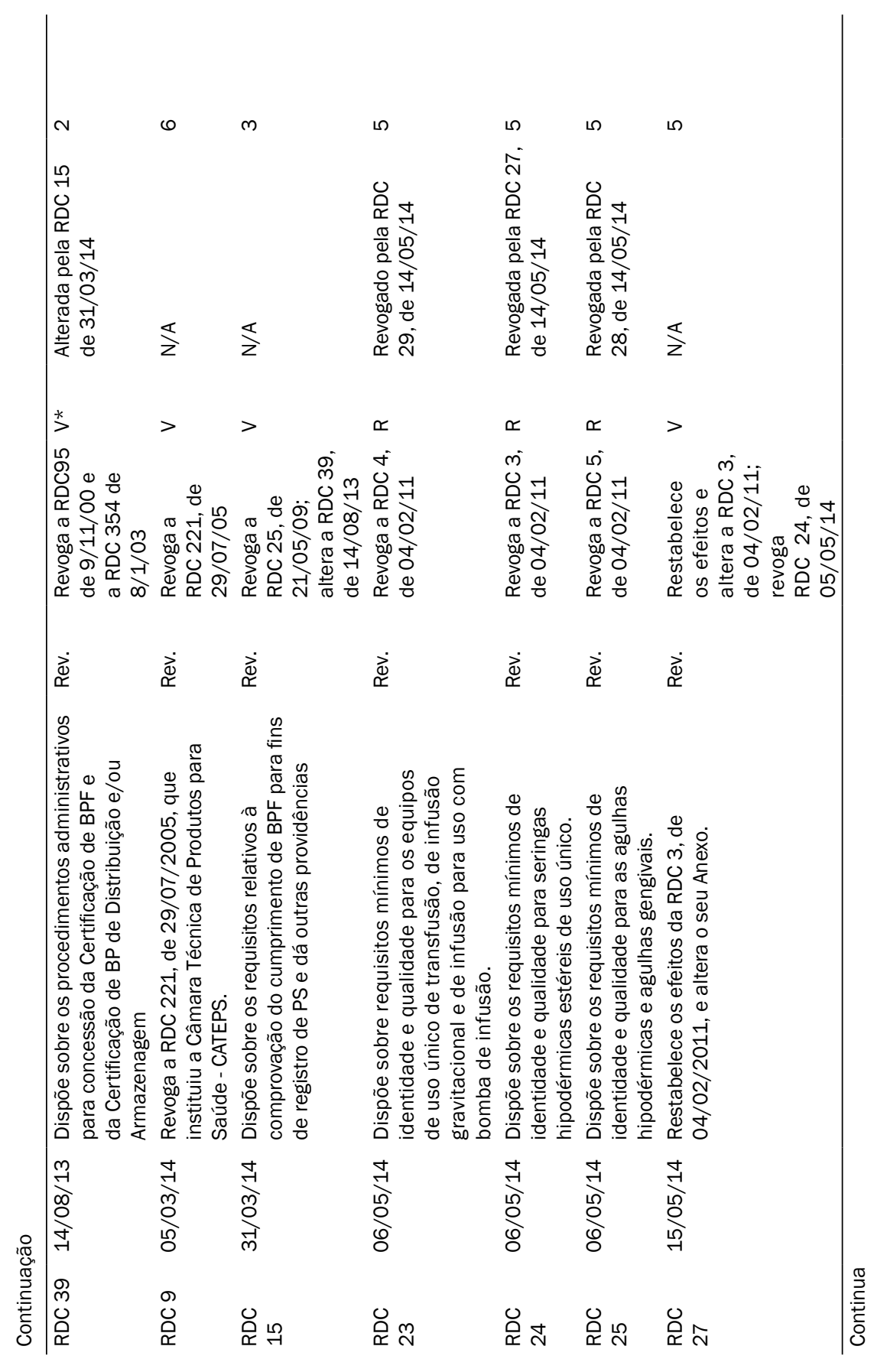


Regulamentação dos materiais médicos no Brasil




Feitoza-Silva M., Nobre P. F. S., Gemal A. L., Leandro K. C.

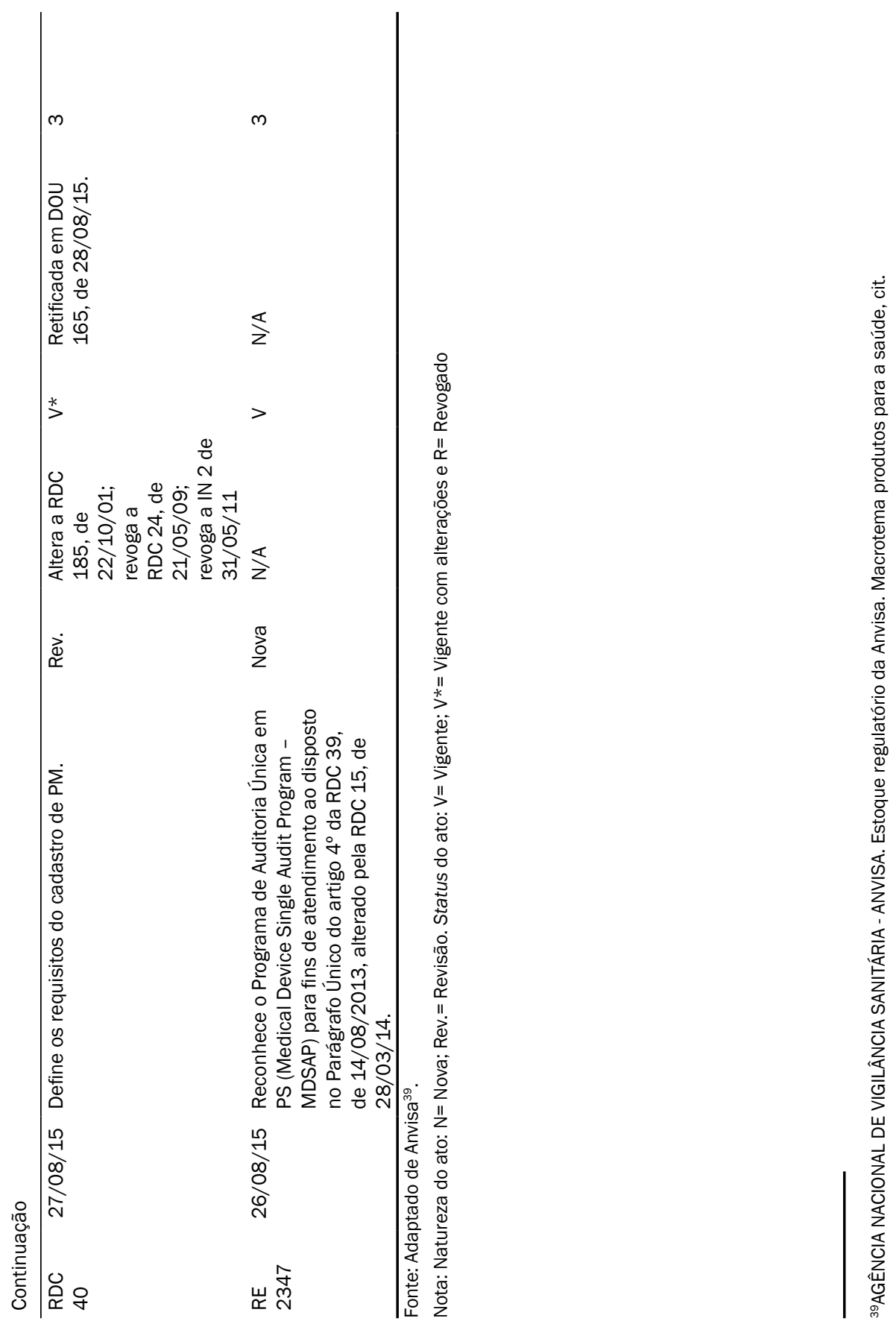


Em fevereiro de 2000, um ano após a criação da Anvisa, foi publicada a RDC 13, específica para empresas de ortopedia técnica. Já em junho surgiu a RDC 59, que tratou das BPF de PS; foi a primeira norma de BPF para produtos sanitários (medicamentos, cosméticos, saneantes e PS) publicada após o surgimento da Anvisa. Esta Resolução foi seguida pela RDC 95, que instituiu o Certificado de BPF e Controle de $\mathrm{PS}^{40}$.

A prioridade para os PSs talvez tenha ocorrido pela carência de normas nessa área, pela questão do risco relacionado a esses produtos e pelo número de reclamações e problemas também relacionados a eles; enfim, são vários motivos que, provavelmente, motivaram a publicação da RDC 59, que, apesar de revogada (2013), tem grande importância e merece destaque em virtude do pioneirismo e dos conceitos que introduziu ${ }^{41}$.

A RDC 16/2013, que tratou das BPF de PS, revogou a RDC 59/2000 e também a Portaria n. 686/1998 e a RDC 167/2004, esta última exclusiva para kits de diagnóstico ${ }^{42}$.

Ainda em 2000, a RDC 97 foi publicada trazendo para os setores regulados e também para todo o SNVS as definições de grupos de produtos e famílias de PS, estratégia até hoje utilizada para as tramitações de registro junto à Gerência de Materiais (Gemat)/ Gerência Geral de Tecnologia e Produtos para Saúde (GGTPS) da Anvisa. O registro em famílias tende a reduzir o número de processos, já que aglutina vários produtos em um trâmite, desde que respeitados critérios, e corta custos diretos da elaboração de processo, bem como os indiretos relativos ao tempo de análise (custo de oportunidade, por exemplo) ${ }^{43}$. Assim como o registro de famílias de produtos, a isenção do registro para novas apresentações ou para produtos com pequenas diferenças ofereceu benefícios de custo financeiro e processual, tanto para a agência quanto para o agente regulado, sem que se observe até 0 momento custo em riscos para a população ${ }^{44}$.

Em 2001, merecem destaque duas normas no âmbito de PS. A primeira delas é a RDC 56, que apresentou uma exigência importante para o PS, considerando que grande parte dos produtos dessa categoria é estéril: as embalagens devem garantir que a esterilidade seja mantida para que a eficácia e a segurança dos produtos permaneçam no momento da pós-comercialização, conforme estabelecido em seus projetos ${ }^{45}$.

A segunda é a RDC 185, que estabeleceu o registro, a revalidação, a alteração e a classificação para PM e que revogou a Portaria n. 1 de 1996 e a Portaria SVS n. 543 de 1997; no caso do registro a RDC incluiu a classificação de risco ${ }^{46,47}$.

\footnotetext{
${ }^{40}$ AGÊNCIA NACIONAL DE VIGILÂNCIA SANITÁRIA - ANVISA. Estoque regulatório da Anvisa. Macrotema produtos para a saúde, cit..

${ }^{41}$ Id. Ibid.

${ }^{42}$ Id. Ibid.

${ }^{43}$ Id. Ibid.

${ }^{44}$ Id. Ibid.

${ }^{45}$ Id. Ibid.

${ }^{46}$ AGÊNCIA NACIONAL DE VIGILÂNCIA SANITÁRIA. Resolução RDC n. 185, de 22 de outubro de 2001, cit.

${ }^{47} A G E \hat{E}$ CIA NACIONAL DE VIGILÂNCIA SANITÁRIA - ANVISA. Estoque regulatório da Anvisa. Macrotema produtos para a saúde, cit.
} 
Essa classificação de risco está diretamente relacionada ao processo de registro desses produtos e também impacta diretamente no campo da tecnovigilância, já que, de acordo com o risco oferecido por um determinado produto, um detentor estará sujeito a uma inspeção em suas instalações ou a comprovações de aspectos relacionados a esse produto, entre outros fatores ${ }^{48,49}$. Apesar de classes de produtos já existirem nas normas que a antecedem, essa resolução ofereceu critérios mais claros para definição de risco, dificultando a subclassificação como forma de o regulado facilitar a tramitação, por exemplo ${ }^{50}$. Em 2002, a RDC 260 publicou um anexo sobre cadastramento conforme previsto pelo artigo 3 da RDC 185/2001 $1^{51,52}$.

Em 2006, a RDC 207 alterou a RDC 185, focalizando o aprimoramento do sistema de classificação de risco: aplicando regras de classificação mais elevadas para produtos que apresentam vários usos. O fabricante fica impedido de solicitar o registro dos produtos com classificação inferior ${ }^{53,54}$.

A necessidade de capacitação de inspetores para concessão de BPF levou à edição da RDC 102/2001, que aprovou o "programa de capacitação de inspetores para verificação de BPF e Controle de PM" e que visava a facilitar a aplicabilidade da RDC 59/2000 pelos inspetores ${ }^{55}$. Observa-se que nenhuma das normas exige, para registro de produtos de classe I, o comprovante de registro outorgado pela autoridade competente de onde o produto é fabricado; isso torna possível a entrada no mercado de produtos de procedência e qualidade duvidosas e coloca em risco pacientes e profissionais que utilizam esses produtos.

O registro de produto classe I no país de origem é controverso, pois em muitos territórios tais países podem operar com sistema de notificação, isenção e certificação como forma de autorização para livre comércio. No entanto, os requerimentos para concessão dessa autorização variam em complexidade.

Ainda em 2002, a Anvisa publicou a RDC 260 também para atualização da tramitação de registro de acordo com o risco, mantendo, por meio da RDC 24/2009, a dispensa do registro dos produtos de classe I e II, e permitindo que esses produtos fossem apenas cadastrados ${ }^{56}$. Posteriormente, outras normas foram publicadas sobre o assunto visando a atualizar e permitir a inclusão de novas tecnologias.

\footnotetext{
${ }^{48}$ BRASIL. Lei n. 6.360, de 23 de setembro de 1976, cit.

${ }^{49}$ BRASIL. Lei n. 6.437, de 20 de agosto de 1977, cit.

${ }^{50}$ AGÊNCIA NACIONAL DE VIGILÂNCIA SANITÁRIA. Resolução RDC n. 185, de 22 de outubro de 2001, cit.

${ }^{51}$ Id. Ibid.

${ }^{52}$ AGÊNCIA NACIONAL DE VIGILÂNCIA SANITÁRIA - ANVISA. Estoque regulatório da Anvisa. Macrotema produtos para a saúde, cit.

${ }^{53}$ AGÊNCIA NACIONAL DE VIGILÂNCIA SANITÁRIA. Resolução RDC n. 185, de 22 de outubro de 2001, cit.

${ }^{54}$ AGÊNCIA NACIONAL DE VIGILÂNCIA SANITÁRIA - ANVISA. Estoque regulatório da Anvisa. Macrotema produtos para a saúde, cit.

${ }^{55}$ Id. Ibid.

${ }^{56}$ Id. Ibid.
} 
Para alguns materiais médicos (agulhas e seringas hipodérmicas, equipos, luvas cirúrgicas e de procedimento, preservativos masculinos, próteses mamárias, dentre outros) temos hoje a certificação compulsória pelo Sistema Brasileiro de Avaliação da Conformidade (SBAC) ${ }^{57}$.

O preservativo foi o primeiro dos materiais a exigir a certificação compulsória - no caso, certificação metrológica "lote a lote", de acordo com a RDC 3/2002, que foi posteriormente revogada pela RDC 62/2008 (alterada em seus prazos de implementação em 2008 e 2009 pelas RDCs 93 e 39, respectivamente) $)^{58}$.

A RDC 221/2005 instituiu a Câmara Técnica de Tecnologia de PS (Cateps), vinculada tecnicamente à GGTPS, com a finalidade de orientar sobre métodos e procedimentos científicos, realizar pesquisas e emitir recomendações e subsidiar a GGTPS nos assuntos de sua competência: equipamentos, produtos para diagnóstico in vitro e produtos para uso em saúde; os "materiais médicos", tema deste estudo, também foram vinculados. A Câmara Técnica foi extinta pela RDC 9/2014 ${ }^{59}$.

Em 2005, tratando de importação, foi publicada a RDC 350 alterada em 2006 e em 2008. Já a A RDC 81/2008 foi alterada em 2011 e 2012 e revogada em 2015 (RDC 10) ${ }^{60}$.

No Brasil, o regulamento vigente sobre reprocessamento de PM foi publicado em 2006, e a RDC 156 dispôs sobre registro, rotulagem e reprocessamento de $\mathrm{PM}^{61}$. A Resolução Específica - RE 2.605, que estabeleceu uma lista de 66 produtos proibidos de reprocessamento no país, e a RE 2.606, que definiu as diretrizes para elaboração, validação e implantação de protocolos de reprocessamento de PM, também foram publicadas em $2006^{62}$. A RDC 156/2006 categorizou os referidos produtos entre passíveis de reprocessamento e de reprocessamento proibido, e estabeleceu que esse enquadramento deve ser feito no registro do produto, quando o fabricante ou importador deve apresentar à Anvisa documentação que fundamente a indicação ${ }^{63}$. As normas referentes a reprocessamento procuraram trazer à normalidade práticas comuns dos agentes regulados, que buscam otimizar o uso de seus recursos e produtos e reduzir custos - considerando que boa parte dos produtos para saúde comercializados no país é importada e vulnerável a flutuações cambiais, fiscais e do mercado internacional. Ofereceram também instrumentos que permitem a fiscalização e o exercício do poder de polícia dentro da estrita legalidade, ordenando e controlando a partir de parâmetros ex ante.

\footnotetext{
${ }^{57}$ Sistema Brasileiro de Avaliação da Conformidade: subsistema do Sinmetro, destinado ao desenvolvimento e coordenação das atividades de avaliação da conformidade no seu âmbito.

${ }^{58}$ AGÊNCIA NACIONAL DE VIGILÂNCIA SANITÁRIA - ANVISA. Estoque regulatório da Anvisa. Macrotema produtos para a saúde, cit.

59ld. Ibid.

${ }^{60}$ Id. Ibid.

${ }^{61}$ Id. Ibid.

${ }^{62}$ Id. Ibid.

${ }^{63}$ Id. Ibid.
} 
Ainda em 2006, exigências acerca de informações econômicas foram publicadas pela RDC 185, incluindo discussões sobre os preços praticados em outros países no momento da revalidação. Alterações foram publicadas na IN 3/2010 $0^{64,65}$.

A RDC 5/2008 estabeleceu requisitos de identidade e qualidade para as luvas cirúrgicas e luvas de procedimentos não cirúrgicos de borracha natural, borracha sintética ou mistura de borrachas natural e sintética após diversas notificações no Sistema Notivisa/Anvisa. Esse regulamento técnico teve seus prazos alterados pela RDC 58/2008 e, ainda, sofreu alteração em 2010. Já em 2011, uma nova legislação para luvas foi publicada, com alterações na tramitação da certificação compulsória do produto ${ }^{66}$.

A RDC 27/2008 estabeleceu novas regras para produtos destinados exclusivamente à exportação e, um mês depois, em 5 de julhos de 2008, a Anvisa publicou regras para a pesquisa clínica (RDC 39) não só para PS, mas para todos os produtos de âmbito sanitário ${ }^{67}$. Além disso, o registro de produtos utilizados no procedimento de pigmentação artificial da pele foi tratado pela RDC 55 do mesmo ano, e seus prazos para implementação pelo setor regulado foram alterados pela RDC 5/200968. Ainda em 2008, foram definidos agrupamentos para o registro de implantes ortopédicos para fins de registro (RDC 59), mas somente em 2009, com a IN 1 , os critérios foram especificados ${ }^{69}$.

Em 2009, temos a publicação da Portaria n. 1.660, que institui o Sistema de Notificação e Investigação em Visa (Vigipós). Nesse momento, observa-se que a preocupação em relação à notificação de queixas técnicas e eventos adversos relacionados a produtos no âmbito sanitário se materializava em ações efetivas ${ }^{70}$.

Também em 2009, publicou-se a RDC 67, que dispôs sobre as normas de tecnovigilância aplicáveis aos detentores de registro de PS e, assim, instituiu a responsabilidade destes quanto à notificação de ocorrências envolvendo seus produtos. Nesse momento, observa-se a preocupação com o monitoramento no pós-uso, algo que é de extrema importância para o SNVS e que permite à Anvisa recolher dados que auxiliem na produção regulatória e de ações fiscalizadoras ${ }^{71}$.

\footnotetext{
${ }^{64}$ AGÊNCIA NACIONAL DE VIGILÂNCIA SANITÁRIA. Resolução RDC n. 185, de 22 de outubro de 2001, cit.

${ }^{65}$ AGÊNCIA NACIONAL DE VIGILÂNCIA SANITÁRIA - ANVISA. Estoque regulatório da Anvisa. Macrotema produtos para a saúde, cit.

${ }^{66}$ Id. Ibid.

${ }^{67}$ Id. Ibid.

${ }^{68}$ Id. Ibid.

${ }^{69}$ Id. Ibid.

${ }^{70}$ BRASIL. Portaria n. 1.660, de 22 de julho de 2009. Institui o Sistema de Notificação e Investigação em Vigilância Sanitária - VIGIPÓS, no âmbito do Sistema Nacional de Vigilância Sanitária, como parte integrante do Sistema Único de Saúde - SUS. Diário Oficial da União, 24 jul. 2009.

${ }^{71}$ AGÊNCIA NACIONAL DE VIGILÂNCIA SANITÁRIA - ANVISA. Estoque regulatório da Anvisa. Macrotema produtos para a saúde, cit.
} 
A proposta da Portaria n. 1.660 foi racional, mas se nota que não houve uma sequência de trabalho que integrasse os sistemas de notificação de estados, municípios e Distrito Federal à Anvisa, que opera o Vigipós ${ }^{72}$. O acesso a esse programa não é tão simples: a instituição deve estar inscrita com senha de acesso ao programa de notificação, mas essa notificação precisa primeiramente ser feita na Visa de seu município, enquanto o produto objeto de notificação é mantido segregado. Outros atos em tecnovigilância que merecem destaque são a IN 1/2012 e a RDC 23/2014 $4^{73}$.

O regulamento técnico para o dispositivo intrauterino (DIU) de cobre foi publicado no final de 2009, revogando uma norma de 1984 (Portaria n. 6) que já estava distante das novas tecnologias do produto. O DIU, juntamente com bolsas plásticas e sangue e conjuntos de aférese, é um produto passível de análise prévia ao registro, conforme definido pela Lei n. 6.437/1977 $74,75,76$.

Diante de questionamentos quanto aos prazos para avaliação de registro e cadastro de produtos na Anvisa no início de 2010, critérios cronológicos para os processos de registro na área de PS foram publicados vinculados ao risco e à prioridade de necessidade da saúde pública. A IN 7/2010 estabeleceu a relação de equipamentos médicos e materiais de uso em saúde que não se enquadram na situação de cadastro, permanecendo a obrigatoriedade de registro, mas foi revogada pela IN $2 / 2011^{77}$.

Apenas em 2011 surgiu a primeira legislação específica para equipos, seringas e agulhas hipodérmicas e gengivais. As RDCs 3, 4 e 5 representaram uma evolução regulatória para esses produtos e, junto às Portarias ns. 501, 502 e 503 (todas de 2011) do Inmetro ${ }^{78}$, foram responsáveis pela consagração da certificação compulsória desses PSs. As RDCs impuseram a certificação, e as portarias explicaram como proceder para realizá-la ${ }^{79,80}$.

\footnotetext{
${ }^{72}$ BRASIL. Portaria n. 1.660, de 22 de julho de 2009, cit.

${ }^{73}$ AGÊNCIA NACIONAL DE VIGILÂNCIA SANITÁRIA - ANVISA. Estoque regulatório da Anvisa. Macrotema produtos para a saúde, cit.

${ }^{74}$ Id. Ibid.

${ }^{75}$ BRASIL. Lei n. 6.437, de 20 de agosto de 1977, cit.

${ }^{76}$ BRASIL. Portaria n. 6, de 06 de julho de 1984. Baixa instruções sobre registro, produção, fabricação, controle de qualidade, comercialização, exposição a venda, propaganda, prescrição aplicação, uso, controle de uso e acompanhamento de usuários de dispositivos intrauterinos (Dius), contendo cobre. Diário Oficial da União, 10 jul. 1984.

${ }^{77} A G$ ÊNCIA NACIONAL DE VIGILÂNCIA SANITÁRIA - ANVISA. Estoque regulatório da Anvisa. Macrotema produtos para a saúde, cit.

${ }^{78}$ A Portaria n. 501, assim como as Portarias 502 e 503 (equipos e seringas hipodérmicas) de 29/12/11 Aprova os Requisitos de Avaliação da Conformidade para Agulhas Hipodérmicas Estéreis para Uso Único e Agulhas Gengivais e institui, no âmbito do SBAC, a certificação compulsória para estes produtos, a qual deverá ser realizada por OCP, acreditado pelo Inmetro, consoante o estabelecido nos Requisitos aprovados.

${ }^{79}$ AGÊNCIA NACIONAL DE VIGILÂNCIA SANITÁRIA - ANVISA. Estoque regulatório da Anvisa. Macrotema produtos para a saúde, cit.

${ }^{80}$ BRASIL. Portaria Inmetro/MDIC n. 501, de 29 de dezembro de 2011. Requisitos de Avaliação da Conformidade para Agulhas Hipodérmicas Estéreis para Uso Único e Agulhas Gengivais Estéreis para Uso Único. Diário Oficial da União, 30 dez. 2011.
} 
Em 2013, foi publicado o novo regulamento técnico das BPF para PS, assim como a RDC 16, que revogou a RDC 59. Seu objetivo foi o de aprimorar os sistemas nacionais de controle e tornar os requisitos aplicáveis a fabricantes brasileiros e importadores. Ainda em 2013, atualizações foram publicadas em relação ao tema BPF (IN 8, RDC 22, RDC 27 e RDC 39), dando suporte e viabilizando a implementação da RDC 16.

Em 2014, atualizaram-se prazos e requisitos mínimos para agulhas, seringas e equipos, e ainda se publicou o regulamento específico para bolsas de sangue, substituindo a Portaria n. 950/1998 (RDC 35). Vale destacar regras que foram publicadas recentemente para agentes clareadores (RDC 6/2015) e a atualização dos ensaios clínicos com regras separadas para PS (RDC 10/2015) ${ }^{81}$.

\section{Avaliação dos assuntos tratados nos atos regulatórios da Tabela 1}

É importante ressaltar que o estudo apresentado na Tabela 1 está restrito aos materiais médicos.

A Tabela 2 foi construída para possibilitar a avaliação do perfil dos assuntos propostos como atos regulatórios pela Anvisa desde a publicação na Lei n. 9.782/1999 $9^{82}$. A partir de documento disponível no site oficial da agência atualizado até 2015, observou-se que 104 atos relacionados a PS foram apresentados, mas somente 73 eram específicos para os materiais médicos. Após revisar o documento, foi necessário acrescentar mais seis regulamentos, revisar e proceder com a regulação proposta. Foi necessário atualizar os dados, e a Tabela 1 então foi consolidada com 79 atos regulatórios classificados conforme a Tabela 2.

Pode-se observar que: não houve publicações com impacto nos materiais médicos nos anos de 2004 e 2007; em 2003 (1) e 2005 (2), temos poucas publicações; e, em 2005, não houve especificidade para PS.

Nos anos de 2003 e 2004, observou-se um grande esforço da Anvisa na área de medicamentos, com destaque aos primeiros regulamentos técnicos para genéricos e similares (RDCs 133 e 135 de 2003), além de diversos outros regulamentos sobre bula, rotulagem, listas restritivas, advertências em material gráfico, vitaminas, homeopáticos industrializados, dentre outros até fevereiro 2004, com o regulamento técnico para medicamentos fitoterápicos. Idem para 2007, quando

\footnotetext{
${ }^{81}$ AGÊNCIA NACIONAL DE VIGILÂNCIA SANITÁRIA - ANVISA. Estoque regulatório da Anvisa. Macrotema produtos para a saúde, cit.

82BRASIL. Lei n. 9.782, de 26 de janeiro de 1999, cit.
} 
Regulamentação dos materiais médicos no Brasil

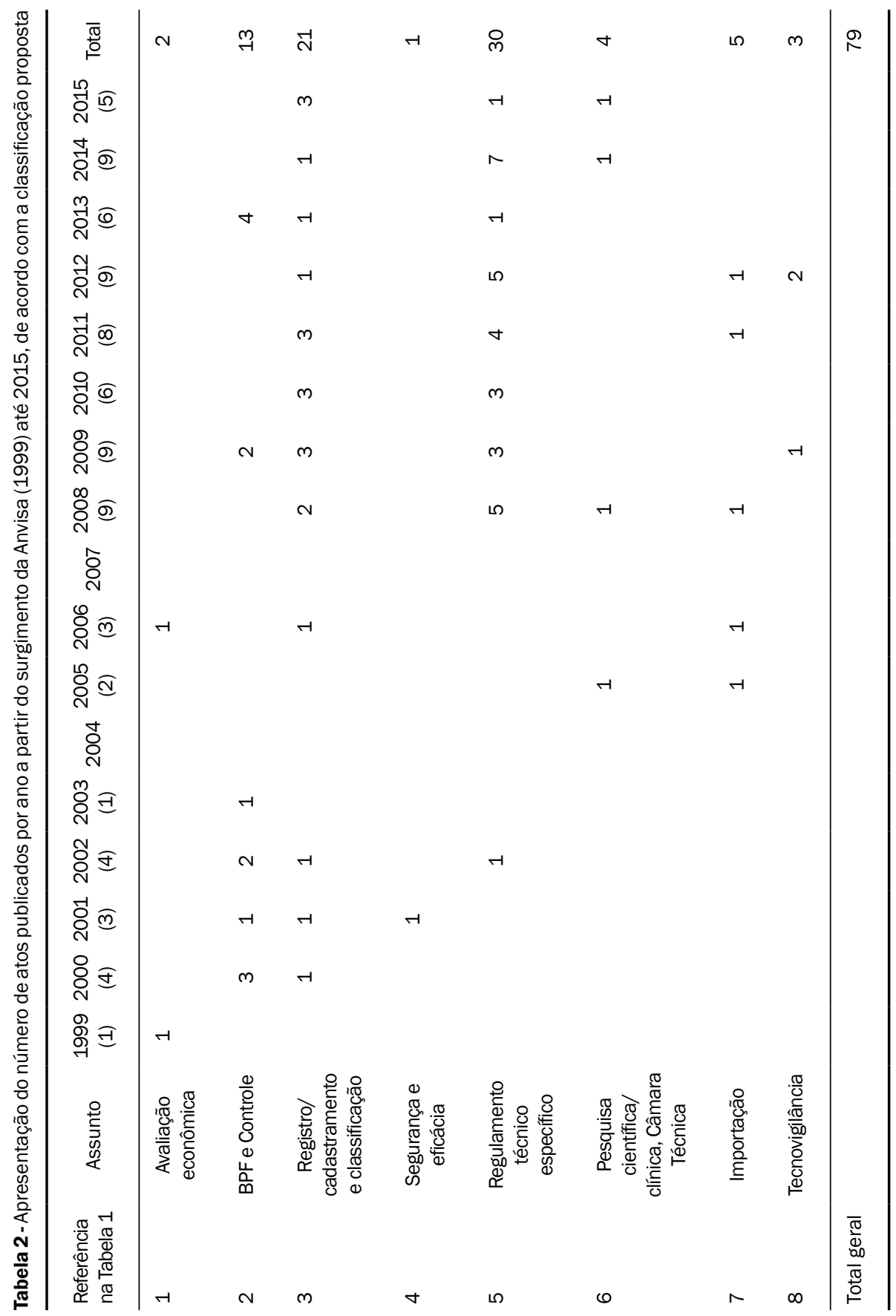


os regulamentos de genérico e similar foram revisados (RDCs 16 e 17) ${ }^{83,84,85,86}$. Tem-se que 1999, 2005 e 2006 são anos com poucas publicações específicas a respeito de materiais médicos.

Ao observarmos a Tabela 2, destacamos os temas 1, 6 e 7 como os de menor especificidade; ou melhor, são temas que impactam a regulação dos materiais médicos, mas também às vezes se referem aos medicamentos e cosméticos, entre outros.

Sobre o tema 2, observamos dois períodos de grande movimentação regulatória: o primeiro foi no ano de 2000 e o segundo ocorreu em 2013, com três publicações - sendo a de maior relevância a RDC 16, que revogou a RDC 59/2000, vigente por $13 \operatorname{anos}^{87}$. As legislações relacionadas ao assunto 2 (BPF) - cerca de $16 \%$ das publicações - representam o terceiro tema de mais prevalência no período estudado (1999-2015).

O tema 3 apresenta atos normativos em quase todos os anos e é o segundo de maior prevalência (21), daí a necessidade da agência de atualização contínua quanto às regras de registro e cadastramento junto ao coordenador da SNVS. As hipóteses para essa produção podem ser várias: desde o aumento do conhecimento sobre o tema, retroalimentado por um sistema de vigilância pós-comercialização, levando ao aperfeiçoamento da etapa pré-comercialização, até necessidades administrativas. Além disso, dentre os produtos de âmbito sanitário, os PS, representam o único grupo que possui uma legislação específica para segurança e eficácia (RDC 56/2001).

Para os PSs, foi publicada em 2001 uma legislação relacionada à segurança e à eficácia, com uma preocupação em um grupo que, em sua maior parte, trata de produtos estéreis e, ainda, perpassa por condições por vezes radioativas, eletromagnéticas e passíveis de lesões irreversíveis ${ }^{88}$.

A Resolução RDC 56/2001 ainda não sofreu alterações e é a única no tema 4. Esta resolução pode ser considerada uma alternativa para as avaliações de aspecto e de danos na embalagem primária de estéreis ${ }^{89}$.

De acordo com a Tabela 2, podemos observar também um número expressivo de regulamentos técnicos específicos (tema 5) a partir de 2008.

\footnotetext{
${ }^{83}$ AGÊNCIA NACIONAL DE VIGILÂNCIA SANITÁRIA. Resolução RDC n. 133, de 29 de maio de 2003. Aprova o Regulamento Técnico para registro de Medicamento Similar. Diário Oficial da União, 2 jun. 2003.

${ }^{84}$ AGÊNCIA NACIONAL DE VIGILÂNCIA SANITÁRIA. Resolução RDC n. 135, de 29 de maio de 2003. Aprova o Regulamento Técnico para Medicamentos Genéricos. Diário Oficial da União, 2 jun. 2003.

${ }^{85}$ AGÊNCIA NACIONAL DE VIGILÂNCIA SANITÁRIA. Resolução RDC n. 16, de 2 de março de 2007. Aprova o Regulamento Técnico para Medicamentos Genéricos. Diário Oficial da União, 5 mar. 2007.

${ }^{86}$ AGÊNCIA NACIONAL DE VIGILÂNCIA SANITÁRIA. Resolução RDC n. 17, de 2 de março de 2007. Aprova o Regulamento Técnico para registro de Medicamento Similar. Diário Oficial da União, 5 mar. 2007.

${ }^{87}$ AGÊNCIA NACIONAL DE VIGILÂNCIA SANITÁRIA - ANVISA. Estoque regulatório da Anvisa. Macrotema produtos para a saúde, cit.

${ }^{88}$ Id. Ibid.

${ }^{89}$ Id. Ibid.
} 
Em 2006, surgiu o Notivisa, uma ferramenta web sob a coordenação da Anvisa que visava a facilitar e sistematizar as notificações. Em 2007, após a implementação dessa estratégia de Vigipós, alguns produtos se destacaram pela quantidade de notificações. Dentre os cinco produtos mais notificados, temos as seringas e agulhas, com queixas técnicas normalmente associadas a falhas e produtos de qualidade baixa ${ }^{90,91}$.

Para atender às falhas apresentadas em segmentos de produtos, optou-se por uma estratégia que combina a edição de normas técnicas, apresentadas aqui, com um avanço de normas pelo Inmetro que viabilizam a certificação compulsória. O primeiro exemplo desse movimento foram os preservativos masculinos (publicação em 2002 e adequações em 2008 e 2009). A estratégia foi a de usar a certificação metrológica como ferramenta para garantia da qualidade sanitária, muitas vezes prejudicada por uma vigilância pós-comercialização deficiente. Supõe-se suprir a deficiência da pós-comercialização com uma garantia pré-comercialização. Posteriormente aos preservativos, foram publicados regulamentos específicos também para agulhas, seringas, próteses mamárias, luvas cirúrgicas e procedimentos. Todos os atos definiram a certificação compulsória para seus respectivos produtos.

O tema 8 trata de tecnovigilância, e a observação da tabela nos remete a movimentos regulatórios recentes (2009 e 2012) pareados à estratégia de valorização da vigilância pós-comercialização, iniciada pela publicação da Portaria n. 1.660/2009 $9^{92,93}$.

"Regulação" é um termo de significados múltiplos, que depende da perspectiva pela qual é abordado. Concepções centradas no Estado tendem a compreender a regulação como um conjunto de normas legais e seus mecanismos de implementação ${ }^{94}$, enquanto concepções mais focalizadas nos atores sociais e na globalização tendem a salientar o aspecto de controle e definidor de políticas das instituições para além do Estado. ${ }^{95}$

Economistas veem a regulação como uma caixa de ferramentas ou como um elemento constituinte das relações de mercado e de propriedade ${ }^{96,97}$.

\footnotetext{
${ }^{90}$ AGÊNCIA NACIONAL DE VIGILÂNCIA SANITÁRIA - ANVISA. Estoque regulatório da Anvisa. Macrotema produtos para a saúde, cit.

${ }^{91}$ BITTENCOURT, Lívia Bretas. Agulhas hipodérmicas: um estudo sobre as principais metodologias para a avaliação do perfil inorgânico das cânulas. 2014. Dissertação [Mestrado] - Universidade Federal Fluminense, Niterói-RJ, 2014.

${ }^{92}$ AGÊNCIA NACIONAL DE VIGILÂNCIA SANITÁRIA - ANVISA. Estoque regulatório da Anvisa. Macrotema produtos para a saúde, cit.

${ }^{93}$ BRASIL. Portaria n. 1.660, de 22 de julho de 2009, cit.

${ }^{94}$ LAFFONT, Jean-Jacques. The new economics of regulation ten years after. Econometrica, v. 62, n, 3, p. $507-$ 537, May, 1994. 10.2307/2951658.

${ }_{95}^{95}$ RAITHWAITE, J. Restorative justice and responsive regulation. Oxford. Oxford University Press, 2002.

${ }^{96}$ STIGLER, G. J. A teoria da regulação econômica. In: MATTOS, Paulo. Regulação econômica e democracia: o debate norte-americano. São Paulo: Ed 34, 2004. p. 23-48.

${ }^{97}$ NORTH, Douglass. Institutions, institutional change and economic performance. Cambridge: Cambridge University Press, 1990.
} 
O estudo dos sentidos da regulação, embora não seja objeto deste trabalho, parte de seu aspecto mais comum na literatura, que é o uso da regulamentação como forma de intervenção em determinado setor, objeto de alguma política pública. É notório que a complexidade dos ordenamentos jurídicos recentes tenha causado a proliferação de normas jurídicas oriundas da regulamentação, ou seja, de normas jurídicas infralegais, produzidas por autoridades administrativas específicas e dotadas de poder normativo. Como exemplo temos, as publicações das Diretorias Colegiadas de agências reguladoras como a Anvisa. ${ }^{98}$

Uma reflexão sobre a produção de normas regulamentares está necessariamente relacionada à melhoria da qualidade da gestão da regulação e a seus aspectos de custo-benefício, que têm sido uma preocupação do Estado: como regular melhor, com mais eficiência na razão de custo e benefício (tanto para a produção quanto para a segurança da população).

\section{Considerações finais}

A construção do arcabouço normativo da Visa, em geral, e dos materiais médicos, especificamente, pareceu obedecer a uma lógica que transita das etapas anteriores, passando pelo registro e comercialização, até a pós-comercialização. Ao longo dos últimos anos, a certificação de BPF vem ganhando importância, conforme identificado no fluxo de edição normativa.

A certificação metrológica, executada por organismos de terceira parte, vem sendo utilizada como ferramenta para buscar garantir qualidade na pós-comercialização dos materiais médicos no Brasil, o que aparece com a publicação de um regulamento técnico específico.

Tal lógica, no entanto, abre mão da abordagem de saúde ao abraçar a certificação compulsória como grande instrumento de garantia da qualidade, a partir de determinado momento na evolução cronológica. Como nos anos anteriores, a análise prévia se constituiu, e ainda se constitui, uma ferramenta importante, apesar de suas falhas - já que representa uma espécie de fotografia instantânea de um momento na produção, sob controle daquele que pleiteia o registro ou comercialização, e não um retrato do que efetivamente é comercializado diuturnamente.

Esse controle é contemplado na norma pelas ferramentas de vigilância, das quais a mais comum é a análise fiscal - que, por sua vez, em geral ocorre por notificação, justamente um grande problema para sistemas de Visa no mundo inteiro. Assim, o SNVS possui uma oportunidade de atuação única, devido ao fato de seu arcabouço normativo possuir modalidades de análise como a de controle (a nosso

\footnotetext{
${ }^{98} \mathrm{AITH}$, Fernando Mussa Abujamra; DALLARI, Sueli Gandolfi. Produção de normas jurídicas sobre saúde no âmbito do estado democrático de direito brasileiro. Cad. Saúde Pública, Rio de Janeiro, v. 30, n. 10, p. 1-3, out. 2014. Disponível em: <http://www.scielo.br/pdf/csp/v30n10/0102-311X-csp-30-10-2032.pdf>. http:// dx.doi.org/10.1590/0102-311XPE011014.
} 
ver nunca implementada) e de monitoramento e, sendo parte do SUS, poder atuar de maneira simples já na aquisição dos produtos mediante controles simplificados, que correspondem a incentivos positivos para as indústrias.

As aquisições públicas parecem ainda mais frágeis nesse cenário, já que, obedecendo à legislação vigente, recebem produtos de preços mais baixos e, por vezes, com a qualidade comprometida. No entanto, o conjunto normativo que disciplina as compras públicas permite a aceitação provisória e a análise de produtos, tornando o maior comprador individual em um regulador potencial do mercado.

As legislações apresentadas somente terão aplicabilidade e eficiência se os profissionais de saúde conhecerem as normas de Visa e tiverem acesso às organizações que podem dar-lhes suporte para melhores decisões, apresentando-se uma alternativa à mera certificação e análise fiscal, promovendo um controle contínuo e potencialmente de baixo custo, desde que integrado à mentalidade de processo de trabalho dos gestores.

Ao mesmo tempo, é preciso confirmar se a certificação compulsória, por si só, opera como incentivo eficaz à melhoria dos produtos de fato comercializados. A resposta é certamente duvidosa.

\section{Referências}

AGÊNCIA NACIONAL DE VIGILÂNCIA SANITÁRIA - ANVISA. Estoque regulatório da Anvisa. Macrotema produtos para a saúde. Disponível em: <http://portal.anvisa.gov.br/wps/ $\mathrm{wcm} /$ connect/d1a159004776681a8874aa97f5c37773/Estoque+Regulat\%C3\%B3rio+PROD UTOS+P+SAUDE.xlsx?MOD=AJPERES >. Acesso em: $16 \mathrm{dez} .2015$.

. Regulação Sanitária. Disponível em: <http://portal.anvisa.gov.br/wps/portal/anvisa/ anvisa/regulacaosanitaria $>$. Acesso em: 05 set. 2015.

AITH, Fernando Mussa Abujamra; DALLARI, Sueli Gandolfi. Produção de normas jurídicas sobre saúde no âmbito do estado democrático de direito brasileiro. Cad. Saúde Pública, Rio de Janeiro, v. 30, n. 10, p. 1-3, out. 2014. Disponível em: <http://www.scielo.br/pdf/csp/ v30n10/0102-311X-csp-30-10-2032.pdf>. http://dx.doi.org/10.1590/0102-311XPE011014.

ALMEIDA FILHO, Naomar Monteiro de. O conceito de saúde e a vigilância sanitária: notas para a compreensão de um conjunto organizado de práticas de saúde. In: SEMINÁRIO TEMÁTICO PERMANENTE DA AGÊNCIA NACIONAL DE VIGILÂNCIA SANITÁRIA, 1., Brasília-DF, out. 2000. Brasília-DF: Ministério da Saúde, 2000. Disponível em: $<$ https://repositorio.ufba.br/ri/bitstream/ri/13870/1/Almeida\%20Filho\%20N.\%20O\%20 CONCEITO\%20DE\%20SA\%c3\%9aDE.pdf>. 
ALVES, Flávia Neves Rocha; PECI, Alketa. Análise de Impacto Regulatório: uma nova ferramenta para a melhoria da regulação na Anvisa. Revista de Saúde Pública, São Paulo, v. 45, n. 4, p. 802-805, ago. 2011. Disponível em: <http://www.revistas.usp.br/ rsp/article/view/33019>. Acesso em: 21 mar. 2017. doi:http://dx.doi.org/10.1590/S003489102011000400023.

BITTENCOURT, Lívia Bretas. Agulhas hipodérmicas: um estudo sobre as principais metodologias para a avaliação do perfil inorgânico das cânulas. 2014. Dissertação [Mestrado] - Universidade Federal Fluminense, Niterói-RJ, 2014.

BRAITHWAITE, J. Restorative justice and responsive regulation. Oxford. Oxford University Press, 2002.

CARVALHO, Mariana Siqueira de. A saúde como direito social fundamental na Constituição Federal de 1988. Revista de Direito Sanitário, São Paulo, v. 4, n. 2, p. 15-31, 2013. Disponível em: <http://www.revistas.usp.br/rdisan/article/view/81181>. http://dx.doi.org/10.11606/ issn.2316-9044.v4i2p15-31.

CENTRO DE VIGILÂNCIA SANITÁRIA. A vigilância sanitária de produtos para saúde. Disponível em: <http://www.cvs.saude.sp.gov.br/apresentacao.asp?te_codigo=3>. Acesso em: 05 set. 2015 .

DI PIETRO, Maria Sylvia Zanella. Direito administrativo. 13. ed. São Paulo: Atlas, 2001.

FERRAZ JUNIOR, Tercio Sampaio. Poder normativo das agências reguladoras à luz do princípio da eficiência. In: ARAGÃO, A. S. de (Coord.). O poder normativo das Agências Reguladoras. Rio de Janeiro: Forense, 2006. p. 271-297.

GAETANI, Francisco, ALBUQUERQUE, Kélvia. Análise de impacto regulatório e melhoria regulatória. In: RAMALHO P. I. S. (Org.). Regulação e agências reguladoras: governança e análise de impacto regulatório - Brasília-DF: Anvisa, 2009. p. 189-196. Disponível em: <http:// portal.anvisa.gov.br/wps/wcm/connect/9829b700474586958fccdf3fbc4c6735/8Regulacao. pdf?MOD=AJPERES $>$. Acesso em: 05 set. 2015.

LAFFONT, Jean-Jacques. The new economics of regulation ten years after. Econometrica, v. 62 , n, 3, p. 507-537, May, 1994. 10.2307/2951658.

LEAL, Rogério Gesta. A quem compete o dever de saúde no direito brasileiro? Esgotamento de um modelo Institucional. Revista de direito Sanitário, São Paulo, v. 9, n. 1, p. 50-69, 2008. Disponível em: <http://www.revistas.usp.br/rdisan/article/view/13101>. http://dx.doi. org/10.11606/issn.2316-9044.v9i1p50-69.

LEVI-FAUR, Davi. Regulation and regulatory governance. In: LEVI FAUR, Davi (Ed.) Hand book on the politics of Regulation. Cheltenham, UK: Edward Elgar Publishing, 2011. p. 3-20. 
LUCCHESE, Geraldo A vigilância sanitária no Sistema Único de Saúde. In: DE SETA, Marismary Horsth; PEPE, Vera Lúcia Edais; OLIVEIRA, Gisele O’Dwyer de (Orgs.). Gestão e vigilância sanitária: modos atuais do pensar e fazer. Rio de Janeiro: Fiocruz, 2006.

MORAES, Eliana Aparecida Silva. O poder regulamentar e as competências normativas conferidas à Agência Nacional de Vigilância Sanitária. Revista de Direito Sanitário, São Paulo, v. 2, n. 1, p. 39-56, 2001. Disponível em: <https://www.revistas.usp.br/rdisan/article/ view/13086>. http://dx.doi.org/10.11606/issn.2316-9044.v2i1p39-56.

MORAES, Reginaldo. Estado, mercado e outras instituições reguladoras. Lua Nova, São Paulo, n. 58, p. 121-140, 2003. Disponível em: <http://www.scielo.br/pdf/ln/n58/a07n58.pdf>. http:// dx.doi.org/10.1590/S0102-64452003000100007.

MOREIRA, Egon Bockmann. Os limites à competência normativa das agências reguladoras. In: ARAGÃO, A. S. de (Coord.). O poder normativo das Agências Reguladoras. Rio de Janeiro: Forense, 2006. p. 173-220.

NORTH, Douglass. Institutions, institutional change and economic performance. Cambridge: Cambridge University Press, 1990.

PIOVESAN Márcia Franke, LABRA, Maria Eliana. Institutional change and political decision-making in the creation of the Brazilian National Health Surveillance Agency. Cad. Saúde Pública, v. 23, n. 6, p. 1373-1382, 2007. Disponível em: <http://www.scielo.br/pdf/csp/ v23n6/11.pdf>. ttp://dx.doi.org/10.1590/S0102-311X2007000600012.

. A construção política da Agência Nacional de Vigilância Sanitária. 2005. Dissertação. (Mestrado em Saúde Pública) - Escola Nacional de Saúde Pública - ENSP -FIOCRUZ, Rio de Janeiro, 2005.

RAMALHO, Pedro Ivo Sebba. Insulamento burocrático, accountability e transparência: dez anos de regulação da Agência Nacional de Vigilância Sanitária. Revista de Serviço Público, Brasília, v. 60, n. 4, p. 337-364, out./dez. 2009.

SILVA, Gustavo Henrique Trindade da. Agenda regulatória e análise de impacto regulatório: a experiência da Agência Nacional de Vigilância Sanitária na aplicação prática de instrumentos inovadores de previsibilidade, transparência e accountability. In: CONGRESSO CONSAD DE GESTÃO PÚBLICA, 4, 2011, Brasília. Anais... Brasília-DF, 2011.

STIGLER, G. J. A teoria da regulação econômica. In: MATTOS, Paulo. Regulação econômica e democracia: o debate norte-americano. São Paulo: Ed 34, 2004. p. 23-48. 
Feitoza-Silva M., Nobre P. F. S., Gemal A. L., Leandro K. C.

Michele Feitoza-Silva - Doutora em Vigilância Sanitária pelo Instituto Nacional de Controle da Qualidade em Saúde da Fundação Oswaldo Cruz (INCQS/FIOCRUZ); mestre em Ciências Farmacêuticas pela Universidade Federal do Rio de Janeiro (UFRJ), graduada em Farmácia Industrial pela Universidade Federal Fluminense (UFF). Professora do Curso de Especialização e da Residência em Vigilância Sanitária do Instituto Nacional de Controle de Qualidade em Saúde (INCQS); Rio de Janeiro/RJ, Brasil. E-mail: michele.feitoza@incqs.fiocruz.br

Patrícia Fernandes da Silva Nobre - Doutora em Saúde Pública pela Escola Nacional de Saúde Pública da Fundação Oswaldo Cruz (ENSP-Fiocruz); mestre em saúde pública pela (ENSP-Fiocruz); bacharel em Direito pela Universidade Gama Filho (UGF). Integrante do Núcleo de Assistência em Direito e Regulação Sanitária do Programa de Pós-Graduação em Vigilância Sanitária do Instituto Nacional de Controle de Qualidade em Saúde. Advogada. Rio de Janeiro/RJ, Brasil.

André Luis Gemal - Doutor em Ciências pela Universidade de Grenoble, na França (Université Scientifique et Medicale - Joseph Fourier); mestre em Química pelo Instituto Militar de Engenharia; graduado em Farmácia e Bioquímica pela Universidade Federal do Rio de Janeiro (UFRJ). Professor Titular do Instituto de Química da UFRJ. Rio de Janeiro/RJ, Brasil.

Katia Christina Leandro - Doutora em Química Analítica pela Pontifícia Universidade Católica do Rio de Janeiro (PUC - RJ). Coordenadora do Programa de Pós-Graduação em Vigilância Sanitária do Instituto Nacional de Controle de Qualidade em Saúde. Rio de Janeiro/RJ, Brasil. 